\title{
Pride and Prejudice: Employment Discrimination against Openly Gay Men in the United States ${ }^{1}$
}

\author{
András Tilcsik \\ Harvard University
}

This article presents the first large-scale audit study of discrimination against openly gay men in the United States. Pairs of fictitious résumés were sent in response to 1,769 job postings in seven states. One résumé in each pair was randomly assigned experience in a gay campus organization, and the other résumé was assigned a control organization. Two main findings have emerged. First, in some but not all states, there was significant discrimination against the fictitious applicants who appeared to be gay. This geographic variation in the level of discrimination appears to reflect regional differences in attitudes and antidiscrimination laws. Second, employers who emphasized the importance of stereotypically male heterosexual traits were particularly likely to discriminate against openly gay men. Beyond these particular findings, this study advances the audit literature more generally by covering multiple regions and by highlighting how audit techniques may be used to identify stereotypes that affect employment decisions in real labor markets.

In recent years, the rights and legal protections of lesbian, gay, bisexual, and transgender (LGBT) people have been at the center of heated debates in the United States. In the absence of a federal law specifically protecting

\footnotetext{
${ }^{1}$ I thank the AJS reviewers for their constructive feedback; Frank Dobbin for invaluable guidance and unwavering encouragement throughout this research; Mary Brinton, Nicholas Christakis, Annemette Sørensen, and members of the Dobbin research group and seminar participants at Harvard and MIT for insightful suggestions; and Darcie DeAngelo, Andrea Flores, and Maureen Sarna for helpful discussions and excellent research assistance. Direct correspondence to András Tilcsik, Harvard University, 2680 Harvard Yard, Cambridge, Massachusetts 02138. E-mail: tilcsik@fas .harvard.edu
}

(C) 2011 by The University of Chicago. All rights reserved.

0002-9602/2011/11702-0005\$10.00 
LGBT employees and job seekers, one debate has focused on sexual orientation discrimination in employment; that is, the behaviors and practices-both deliberate and nonconscious - that disadvantage individuals of a particular sexual orientation over individuals of another sexual orientation in employment contexts (Romer v. Evans, 517 U.S. 620, $116 \mathrm{~S}$. Ct. 1620, 134 L. Ed. 2d 855 [1996]; Badgett 2001; Rubenstein 2002; Hull 2005; Herszenhorn 2007). Although scholars have produced a considerable amount of research relevant to this debate (Badgett et al. 2007), most of the literature has focused on wage inequality and has produced little direct evidence about the difficulties that LGBT people might face in obtaining a job. Thus, we can currently only speculate about the extent and patterns of sexual orientation discrimination in the hiring process. This is a significant omission because hiring discrimination is an important inequalitygenerating mechanism with potentially powerful effects on a job seeker's access to a broad range of opportunities (Petersen and Saporta 2004; Pager 2007). More generally, the current focus on wage inequality may be limiting because even when wage regressions demonstrate significant income differences between two groups (e.g., LGBT and heterosexual employees), skeptics might argue that the observed gap reflects unobserved differences in employee productivity or preferences rather than discrimination (cf. Farkas and Vicknair 1996; Berg and Lien 2002). Thus, the lack of direct evidence about sexual orientation discrimination, and hiring discrimination in particular, limits our understanding of the nature and extent of inequalities faced by LGBT Americans.

I begin to address this lacuna by directly examining hiring discrimination against openly gay men. In doing so, I present results from the first largescale audit study of sexual orientation discrimination in the United States. Limiting the scope of this study to one LGBT group—gay men—was advantageous because the precise nature of prejudice based on sexual orientation might vary across different LGBT groups. For example, while gay men are commonly stereotyped as feminine or effeminate (Madon 1997), lesbians are often believed to be overly masculine (Ward 2008). Given these different perceptions, employer behavior toward job seekers from different LGBT groups may not be uniform. By focusing on a single group-and leaving it to future research to explore discrimination against other LGBT groups-it was possible to delve more deeply into the nature of discrimination against gay men. To do so, I responded with a pair of fictitious but ostensibly real résumés to 1,769 postings of white-collar, entry-level jobs in seven states, randomly assigning a signal of sexual orientation to each résumé. The findings from this study provide evidence about the extent of discrimination as well as the factors that affect the likelihood of discrimination, including local attitudes toward gay men, the presence of antidiscrimination laws, and the extent to which employers value stereotypically 
male heterosexual personality traits. These findings contribute to the literature on inequality and employment discrimination in three ways.

First, by reporting the results of an audit study, I provide direct evidence about the understudied area of sexual orientation discrimination in hiring. Since the audit methodology experimentally controls for the fictitious job seekers' human capital, I am able to test whether job applicants who appear to be gay are treated differently than equally qualified heterosexual men at the first critical stage in the employee selection process. Thus, this study presents more direct evidence of discrimination than do analyses of wage differences, studies of discrimination complaints, or surveys that capture self-reported employee experiences.

Second, by analyzing detailed data about the nature and location of jobs in my sample, I begin to unpack the phenomenon of hiring discrimination against openly gay men and identify the contexts in which it is most and least prevalent. Indeed, while many previous audit experiments have been limited to a single city or two, this study presents evidence from seven geographically dispersed states that vary in both the local attitudes toward gay men and the presence of pertinent antidiscrimination laws. I find dramatic variation in the level of hiring discrimination across these areas: while there is severe discrimination in some states, there is little or no discrimination in others. Exploring this variation provides some insight into how legal environments and local attitudes affect the labor market situation of gay people.

Third, this study provides evidence about the powerful role of stereotypes in sexual orientation discrimination. I find that employers who seek applicants with stereotypically male heterosexual traits are particularly likely to engage in discrimination. This finding suggests that discrimination is partly rooted in specific stereotypes about gay men and that these stereotypes loom large in U.S. labor markets. Thus, this study suggests a mechanism of discrimination to which prior audit studies have given relatively little attention: stereotyping.

In addition to these contributions, this study also advances the audit methodology more generally. Existing audits of employment discrimination-whether they focus on race, gender, or other characteristics-have typically collected data from just a single city or, at most, two cities (Pager 2007). The present study is the first audit experiment to include employers from multiple states and to reveal significant regional differences in the level of discrimination. Moreover, this audit study is the first to demonstrate that the level of discrimination depends partly on the personality traits that employers seek (cf. Weichselbaumer 2004). Thus, this study highlights the potential of the audit methodology for revealing the stereotypes that most potently affect employment decisions in actual labor markets. 


\section{PRIOR RESEARCH}

Starting with Badgett's (1995) seminal study, much of the literature on sexual orientation discrimination in the United States has focused on compensation (Klawitter and Flatt 1998; Allegretto and Arthur 2001; Badgett 2001; Clain and Leppel 2001; Berg and Lien 2002; Black et al. 2003; Blandford 2003; Carpenter 2007; Antecol, Jong, and Steinberger 2008). Controlling for human capital, these studies have found that gay men earn 10\%-32\% less than heterosexual men (Badgett et al. 2007). Although these studies generated important evidence, they focused on earnings, rather than the hiring decision, and were not designed to provide direct evidence about discrimination. Indeed, regression analyses that define discrimination as unexplained income differences may lead to biased estimates of discrimination if differences in employee productivity or preferences are observed incompletely (Farkas and Vicknair 1996; Neal and Johnson 1996; Berg and Lien 2002; Correll, Benard, and Paik 2007; Pager, Western, and Bonikowski 2009).

Another line of research examined employee self-reports and found that many LGBT individuals report experiencing some form of discrimination in the workplace (e.g., Badgett, Donnelly, and Kibbe 1992; Croteau 1996; Badgett 1997). The generalizability of these studies, however, is limited because they rely on convenience samples and capture subjective perceptions, rather than the actual incidence, of discrimination (Badgett et al. 2007). A third approach focused on the number of employment discrimination complaints that LGBT employees filed in states that outlaw sexual orientation discrimination. Rubenstein (2002), for example, found that the per capita rate of complaints about sexual orientation discrimination was comparable to the rate of sex and race discrimination complaints. However, like self-reports, complaint rates do not necessarily represent the actual incidence of discrimination. Clearly, some employees who experience discrimination may never file a complaint, while others may file an unfounded complaint.

Seeking more direct evidence for discrimination, some researchers have adopted an experimental approach. Crow, Fok, and Hartman (1998), for example, asked full-time employees in a southern city to select six out of eight fictitious applicants for an accounting position. For all combinations of gender and race, respondents were more likely to eliminate homosexual candidates than heterosexual candidates. Similarly, Horvath and Ryan (2003) instructed undergraduates to rate résumés for which sexual orientation and gender were experimentally manipulated. Gay and lesbian applicants received lower ratings than heterosexual men but higher ratings than heterosexual women. Taking a somewhat different approach, Hebl et al. (2002) conducted a field experiment in which male and female con- 
federates applied for retail jobs in a mall of a Texas metropolis. For each store, the confederates were randomly assigned to wear a baseball hat with the words "Gay and Proud" or "Texan and Proud." This experiment measured both interpersonal bias (e.g., differences in interaction duration) and formal bias (e.g., differences in job offers and callbacks) and found evidence for the former but not the latter.

Although these experiments represent an important first step toward directly measuring hiring discrimination, they have significant limitations. First, all three experiments were limited to a single context - a single city, university, or mall area. Thus, it is unclear how accurately the results reflect broader patterns of discrimination and how the extent of discrimination might vary across different contexts. Second, in two of these studies, the decision makers knew that they were participating in an experiment and that their choices had no consequences on real hiring outcomes (Crow et al. 1998; Horvath and Ryan 2003). Whether these decision makers would make the same hiring choices in a real employment context, faced with real incentives and constraints, remains unclear. Indeed, the extent to which these experiments mimic real decision making may be significantly limited. For example, in the study by Crow et al. (1998), participants were simply presented with several combinations of race, gender, and sexual orientation (e.g., "white heterosexual male"), rather than the fictitious candidates' full résumés-an unrealistic scenario in most employment contexts. Finally, the sample of experimental participants may further limit generalizability. In Horvath and Ryan's sample, in particular, the participants were college students rather than employers, and nearly $80 \%$ of them were white women-a sample that is not representative of the U.S. population or even the undergraduate population (Badgett et al. 2007).

\section{AN AUDIT APPROACH}

To overcome the above-described limitations, I conducted a large-scale audit study of discrimination against gay men. Audit studies apply experimental techniques to real world employment contexts and fall into two categories: in-person audits and correspondence tests (Pager 2007). In-person audits involve sending pairs of experimental confederates-who are matched on a variety of relevant characteristics but differ, for example, in their race or gender-to apply for jobs with real employers (e.g., Pager 2003; Pager et al. 2009). Correspondence tests are based on a similar approach but use fictitious matched résumés rather than actual job applicants (e.g., Bertrand and Mullainathan 2004; Correll et al. 2007). In both cases, researchers examine whether a characteristic of interest (such as gender or race) affects 
the probability that an applicant receives a positive response (such as a callback or a job offer).

The audit methodology offers important advantages. By experimentally controlling for human capital factors that might be confounded with minority status, audit studies provide more direct evidence about the causal impact of discrimination than do wage regressions (Pager 2007). By gathering such evidence in a real employment context from real employers, audit studies are also more generalizable than studies with undergraduate participants and experiments in which participants know that their choices will not affect real hiring outcomes (Correll et al. 2007). Of course, audit studies are not without limitations. Critics, for example, have pointed to the difficulty of matching real persons on all dimensions that might affect productivity (e.g., Heckman 1998) and have noted that, because auditors know the purpose of the study, in-person audits are subject to experimenter bias (Bertrand and Mullainathan 2004). However, by relying on résumés, rather than real auditors, correspondence studies can circumvent these problems (Bertrand and Mullainathan 2004; Pager 2007).

Despite the advantages of the audit methodology, only a handful of studies have taken an audit approach to sexual orientation discrimination, with the only in-person audit the one by Hebl et al. (2002). That study, however, was based on a relatively small sample (84 employer-job-seeker interactions) and was limited to a single mall area. Correspondence audits measuring sexual orientation discrimination are also rare. Three decades ago, Adam (1981) mailed a total of 163 nearly identical résumés to Ontario law firms. The résumés were only differentiated by gender and sexual orientation, which was signaled by indicating-on roughly half of the résumés-that the applicant was active in the "Gay People's Alliance." For both men and women, the gay-labeled résumés led to fewer interview invitations than the unlabeled résumés. The generalizability of these results is limited, however, because of the small scale of the study. Among male applicants, for example, the gay-labeled and unlabeled résumés led to just four and seven interview invitations, respectively-a statistically insignificant difference.

A correspondence test with a much larger sample has explored discrimination against lesbians in Austria (Weichselbaumer 2003). In this study, 1,226 applications with female names were sent out in response to 613 clerical vacancies in the greater Vienna area. One résumé in each pair was assigned a signal of lesbian orientation (volunteer experience in the gay and lesbian movement), while the other résumé was assigned a control signal (volunteer experience in a nonprofit cultural or educational center). All else equal, résumés indicating a lesbian orientation were less likely to elicit an invitation for an interview. More recently, 
Drydakis (2009) sent pairs of applications from fictitious male job seekers to 1,714 job openings in Athens, Greece. The signal of homosexual orientation was past volunteer involvement in the "Athenian Homosexual Community," and the control signal was past volunteer activity in an environmental group. While applications with the control signal elicited a callback in $40 \%$ of the cases, less than $14 \%$ of the gay-labeled applications were successful.

To date, however, there has been no large-scale audit of sexual orientation discrimination in the United States. In addition, no audit study in any country has examined sexual orientation discrimination across geographic areas that vary significantly in the popular acceptance of homosexuality or in the extent to which local laws protect LGBT employees. Moreover, existing studies have not investigated whether employers who seek applicants with certain characteristics are more likely to discriminate against gay men. I begin to address these lacunae.

\section{DISCRIMINATION, REGIONAL VARIATION, AND STEREOTYPES}

In this section, I first discuss the plausibility of hiring discrimination against gay men in the United States. I then consider how the likelihood of discrimination may vary across contexts. Although my empirical analyses control for numerous factors that may influence the level of discrimination, I focus below on two sources of variation. First, I consider geographic variation that may stem from differences in local attitudes toward gay men and from differences in the level of legal protection available to them. Second, I discuss the kind of variation in the level of discrimination we might observe if stereotypes of gay men play a role in hiring decisions.

Before proceeding, however, a point of clarification is in order. It is important to note that, in the context of a correspondence audit, one cannot clearly distinguish between discrimination against gay job seekers and discrimination against openly gay job seekers. Since employers have no information about applicants beyond what is provided on the résumé, a correspondence audit is suitable for capturing discrimination against gay applicants who provide information that somehow signals their sexual orientation. This issue, of course, is not unique to audit studies of sexual orientation; indeed, it surfaces whenever an audit experiment focuses on a partially or fully concealable characteristic, such as political affiliation, religion, or parental status (Correll et al. 2007). Thus, when using the phrases "sexual orientation discrimination" or "discrimination against gay men" in the context of an audit study, I refer to discrimination on the basis of disclosed sexual orientation rather than sexual orientation in a more general sense. 


\section{Callback Discrimination}

As noted earlier, self-reports, analyses of discrimination complaints, and laboratory experiments cannot provide direct evidence of sexual orientation discrimination. Nevertheless, as the literature review above indicates, such studies consistently point to the possibility of employment discrimination against gay men (Badgett et al. 2007). Public opinion data provide further support for this hypothesis. While Americans have become more accepting of gay people over the past few decades, they are still significantly less tolerant than the citizens of most advanced democracies in Europe (Saad 2005). Surveys indicate that approximately half of all Americans express an "unfavorable" opinion of gay men, and nearly one in three Americans has a "very unfavorable" view (Pew Research Center 2003). Particularly relevant for employment discrimination is the finding that $20 \%$ of survey respondents in the United States report feeling uncomfortable around homosexuals (Pew Research Center 2003). Similarly, research in status characteristic theory (Berger et al. 1977) suggests that sexual orientation is a status characteristic in the United States and that heterosexual is a more positively evaluated state than homosexual (Johnson 1995). Different performance expectations are associated with each state of sexual orientation, and respondents tend to assign higher performance expectations to heterosexuals than to homosexuals (Webster, Hysom, and Fullmer 1998).

Accordingly, I expect that gay job seekers will face discrimination in U.S. job markets. In particular, I focus on discrimination that occurs at the initial stage of the employee selection process and predict that applications from gay men will be less likely to elicit an interview invitation (or "callback") than applications from equally qualified heterosexual men. As several researchers noted, this first step in the employee selection process is a critical stage because it often represents a crucial barrier to employment for minorities (Bendick, Brown, and Wall 1999; Pager 2003; Drydakis 2009; Pager et al. 2009). Yet, because of data limitations, researchers generally know less about discrimination in the hiring process than about discrimination in promotion, firing, or wage setting (Petersen and Saporta 2004). Thus, this study-like audit studies in generalfocuses on a relatively understudied area within the wider labor market literature.

\section{The Geography of Discrimination}

Prior audit studies of racial, gender, and sexual orientation discrimination have typically focused on a limited geographic area-often just a single city or two (e.g., Pager 2003; Bertrand and Mullainathan 2004; Drydakis 
2009; Pager et al. 2009). As a result, it is sometimes difficult to know whether variation in the observed level of discrimination against a given group is due to differences between experimental designs or to regional variation in the actual prevalence of discrimination (Pager 2007). When studying discrimination against gay men in the United States, limiting the scope of an audit experiment to a single city would be particularly disadvantageous. Indeed, regional differences in the level of tolerance toward gay men and in antidiscrimination laws may lead to geographic variation in the incidence of discrimination.

Public opinion polls indicate considerable regional variation in attitudes toward gay men. While almost half of Americans in the Northeast and the West have a favorable view of gay men ( $48 \%$ and $45 \%$, respectively), only slightly more than a third of respondents express similar views in the Midwest (35\%) and even fewer in the South (29\%; Pew Research Center 2003). Support for gay rights follows the same regional pattern. From nondiscrimination laws to hate crime legislation, public support for policies to protect gay rights is strongest in the Northeast and the West and weakest in the South (Lax and Phillips 2009). Similar regional differences are borne out by a wide range of studies, from surveys of high school students (Gilbert 2001) to analyses of court cases (Pinello 2003, pp. 10-12). Taken together, these findings suggest significant regional differences in the social acceptance of gay men. If such differences are reflected in the hiring process, callback discrimination will be more likely in areas with less tolerant attitudes (e.g., the South) than in areas with more accepting attitudes (e.g., the Northeast).

The adoption of state laws that prohibit sexual orientation discrimination follows a similar geographic pattern. At the time of this study, 20 states and the District of Columbia prohibited sexual orientation discrimination in the private sector, but most of these states were in the Northeast and the West. For example, all states in New England and, with the exception of Alaska, all Pacific states had passed such legislation. By contrast, only four out of 12 midwestern states banned sexual orientation discrimination, and in the South, only two states adopted such laws. The geographic distribution of counties and cities that ban sexual orientation discrimination in private employment was roughly similar, with relatively few antidiscrimination laws in southern cities and counties. Notably, however, such laws have been passed in some major cities in the South and the Midwest, including Atlanta, Austin, Chicago, Dallas, and Detroit. ${ }^{2}$

Whether such laws are effective in reducing discrimination is an empirical question. There is only scant evidence on this issue, and it is mostly

\footnotetext{
${ }^{2}$ The Human Rights Campaign (http://www.hrc.org) maintains a list of cities and counties that prohibit sexual orientation discrimination in employment.
} 
from studies of wage discrimination. For example, Klawitter and Flatt (1998) found that antidiscrimination laws had a positive effect on the earnings of gay men, suggesting a reduction in wage discrimination, but this effect became statistically insignificant after controlling for the sociodemographic characteristics of the local population. Whether state and local laws reduce discrimination in the hiring process is, of course, a different empirical question. I begin to address this question by covering areas that vary in the presence of antidiscrimination laws.

\section{The Role of Stereotypes}

Stereotypes are socially shared sets of implicit or explicit beliefs about the typical characteristics of members of a social group (Banaji 2002; Padavic and Reskin 2002). Stereotyping is the process by which stereotypes are used in judgments about a social group or its individual members. Since stereotyped judgments simplify and justify social reality, stereotyping has potentially powerful effects on how people perceive and treat one another (e.g., Banaji, Hardin, and Rothman 1993; Fiske 1998; Reskin 2001; Ridgeway 2009). Indeed, laboratory experiments suggest that stereotyping may play an important role in judgments that affect hiring decisions (Davison and Burke 2000; Rudman and Glick 2001).

In the audit literature, however, stereotyping has received relatively little empirical attention. Although researchers often speculate that the discrimination they observe may be, in part, due to stereotyping (e.g., Riach and Rich 2006; Pager et al. 2009), these conjectures have rarely been examined directly. One notable exception is a correspondence test in Austria that compared the callback rates of three fictitious job applicants (a man, a feminine woman, and a masculine woman) across job postings that emphasized different personality traits (e.g., "powerful," "dynamic," "friendly"; Weichselbaumer 2004). This research design made it possible to assess whether employers looking for job candidates with stereotypically masculine traits favored men over women and masculine women over feminine women. The callback rates, however, did not differ across job postings that emphasized different personality requirements.

I adopt a similar approach. If stereotyped judgments influence callback decisions, employers should be more likely to engage in discrimination if they value and emphasize attributes that gay men are stereotypically perceived to lack. What might these attributes be? Research suggests that gay men are often perceived to exhibit behaviors associated with "feminine" characteristics; for example, they are commonly seen as sensitive, emotional, gentle, affectionate, and passive (Gurwitz and Marcus 1978; Page and Yee 1986; Jackson and Sullivan 1989; Madon 1997). Indeed, a general finding is that people frequently perceive gay men to be feminine or effeminate 
(Haddock, Zanna, and Esses 1993; Madon 1997; see also Connell 2005). Consequently, gay men are often seen as lacking "toughness" and "masculinity" (Madon 1997).

Even a quick perusal of job postings reveals that it is not uncommon for employers to emphasize personality characteristics that are perceived as traits typical of heterosexual men, such as decisiveness, assertiveness, and aggressiveness (Bem 1974; Madon 1997; Gorman 2005). Indeed, searches in online job databases often return hundreds of postings in which employers seek, for example, "an aggressive, motivated self-starter," "an assertive associate," or "a decisive, results-oriented leader." This emphasis on stereotypically male heterosexual characteristics, in turn, may be associated with a higher likelihood of discrimination against gay men. If stereotypes of gay men - as feminine, passive, gentle, or lacking "toughness"play a significant role in callback decisions, employers who characterize their ideal job candidate with stereotypically male heterosexual traits should be particularly likely to engage in discrimination.

\section{METHODS}

In what follows, I first consider the challenge of signaling sexual orientation on a résumé and explain how I addressed that challenge. I then describe the details of my audit experiment, the sample of jobs, and the variables used in regression analyses.

\section{Signaling Sexual Orientation}

An important challenge in résumé-based audit studies is to signal the characteristic of interest without introducing a confounding factor into the analysis. For example, in studies of racial discrimination, signaling race with distinctively African-American names (e.g., Bertrand and Mullainathan 2004) may also signal low socioeconomic status. As a result, it may be difficult to untangle the effect of race and class on discrimination (Pager 2007). Similarly, in a study of sexual orientation, a résumé item that indicates experience in a gay and lesbian organization may signal more than just the applicant's sexual orientation. As Weichselbaumer (2003, p. 635) pointed out, employers may perceive openly gay applicants as tactless or lacking business savvy because they list an irrelevant experience on their résumé, simply "trumpeting" their sexual orientation. In addition, perceiving such applicants as radical or liberal, employers may discriminate against them for their perceived political views and activism, rather than their sexual orientation (Badgett et al. 2007). Moreover, if the "control organization" that is assigned to the résumé of the ostensibly 
heterosexual applicant is not carefully chosen, it may lead to differences in the applicants' perceived level of human capital, making it difficult to assess the extent of discrimination. For example, Drydakis (2009) used a gay community organization as the signal of homosexual orientation and an environmental group as the control organization. A potential issue is that employers may perceive experience in an environmental organization as more valuable than experience in a gay community group, even if they are not biased against gay employees; for example, they may see the gay group as a primarily social organization and assume that volunteering for the environmental group is a more important and meaningful activity. In that case, differences in callback rates would lead us to overestimate the level of discrimination.

I took several steps to address these issues. First, the fictitious job seekers in this study were graduating college seniors applying for entrylevel jobs. For this population of applicants, listing résumé items that describe volunteer experiences in a political, cultural, ethnic, religious, or other identity-based campus organization is common practice, especially if the experience involves an elected position with nontrivial responsibilities. ${ }^{3}$ For example, while simple membership in a college's Asian American Association or Republican Club would usually be omitted from the résumé, job seekers would typically list their experience as an officersuch as treasurer or president-in such groups. Thus, in the case of college seniors, listing involvement in political or identity-based groups is, in itself, less likely to be perceived as unprofessional or unusual than in the case of experienced job seekers. Indeed, in the absence of long-term, off-campus work experiences, college seniors often rely on activities in campus clubs as important indicators of their human capital (e.g., Leape and Vacca 1995).

Second, to signal homosexual orientation, I chose an experience in a gay community organization that could not be easily dismissed as irrelevant to a job application. Thus, instead of being just a member of a gay and lesbian campus organization, the applicant served as the elected treasurer for several semesters, managing the organization's financial operations (see appendix fig. A1). Accordingly, rather than focusing on the organization's nature or goals, this résumé item explicitly emphasized the

\footnotetext{
${ }^{3}$ A review of sample résumés in career guides (e.g., Leape and Vacca 1995) and actual student résumés posted on recruitment websites confirms this. Indeed, listing even a gay and lesbian organization in this way is consistent with the advice of career service offices. For instance, the Career Services office at the University of Pennsylvania suggests that, "if you do choose to include LGBT-related information on your resume, be certain to put the emphasis on accomplishments that are relevant to employers. Highlight leadership, budgeting, event planning, public speaking and organizational skills" (emphasis added; http://www.vpul.upenn.edu/careerservices/LGBTguide.html).
} 
applicant's managerial and financial skills. Thus, the applicant's participation in this organization could be seen as a meaningful, valuable experience with potentially important transferable skills. In other words, omitting this experience from the résumé would have meant concealing relevant and nontrivial human capital. In addition, since the applicant was the treasurer, rather than, say, the political chair or outreach officer of the group, this experience was primarily financial and organizational (fig. A1) rather than that of a political activist. This aspect of the position helps mitigate the concern that the reason for discrimination was a bias against political activists rather than a bias against gay men (Badgett et al. 2007). Similarly, given the heavy emphasis on the specific financial and organizational activities associated with the treasurer position, it would be difficult to dismiss this résumé item as a social activity or a way of simply trumpeting the applicant's sexual orientation.

Third, I used a control organization to ensure that any observed differences in callbacks could be attributed to antigay discrimination rather than other factors. An important consideration was that participation in a gay organization might be associated with progressive, liberal, or leftist political views (Badgett et al. 2007). Thus, if I had used an apolitical control organization (or no control organization at all), observed differences in callbacks might have been attributable to discrimination based on either sexual orientation or political affiliation, and it would have been impossible to determine the net effect of sexual orientation. Accordingly, to determine whether there is a "gay penalty" above and beyond the possible effect of political discrimination, I chose a control organization that is associated with leftist or progressive views. Indeed, pilot results supported this rationale for using a left-wing group (rather than an apolitical group) as the control organization. ${ }^{4}$ At first glance, a campus chapter of college Democrats (e.g., "Bowdoin College Democrats") might seem suitable for this purpose. However, since Democratic campus groups are typically larger than gay and lesbian student groups, leadership experiences in a Democratic organization may seem more valuable than similar experiences in a gay organization. To avoid this problem, the control group

\footnotetext{
${ }^{4}$ The goal of the pilot study was to assess the feasibility of a full-scale audit experiment. The pilot involved sending résumé pairs in response to 86 job postings, following a similar protocol as the main study (see the section entitled "Résumés and Randomization"). The results (which are available upon request) indicate that employers in politically conservative areas might discriminate against ostensibly heterosexual job applicants who participated in a leftist student group in college (vis-à-vis ostensibly heterosexual applicants who did not signal participation in such a group.) Thus, if the control organization in the main study sent no left-wing political signal, any observed difference in callback rates might be an overdetermined outcome as it could be attributable to either antigay discrimination or political discrimination.
} 
was a small left-wing campus organization (the "Progressive and Socialist Alliance"; P\&SA) rather than a larger and better-known group. ${ }^{5}$

An additional advantage of using a political control organization that, like the PS\&A, falls outside the mainstream of partisan politics is that disclosing one's commitments to such a group may indicate a lack of business savvy to employers, especially in the case of white-collar business jobs. This aspect of the experiment further mitigates the concern that observed differences in callbacks may be due to the perception of openly gay applicants as unsavvy or tactless. ${ }^{6}$ Nevertheless, even with these precautions, such a perception may still play some role. The issue of perceived tactlessness, however, does not refute the existence of discrimination; rather, it constitutes one possible explanation for why some employers might engage in discrimination. After presenting empirical analyses, I will consider this issue in more detail and in light of my findings.

\section{Résumés and Randomization}

Over a six-month period in 2005, I sent fictitious résumés, via e-mail, to advertisements for full-time, entry-level positions on three recruitment websites targeted at college seniors and recent graduates. ${ }^{7}$ I sent two résumés in response to each job posting, with one day or less in between.

\footnotetext{
${ }^{5}$ A casual survey of college websites reveals that a progressive, socialist, or other similar left-wing student group exists in numerous liberal arts college campuses. These groups are, however, typically smaller and somewhat less common than Democratic (or Republican) campus groups.

${ }^{6}$ In addition, if the P\&SA indicates more of an activist orientation than does the gay organization, and if employers prefer not to hire activists, the estimates of antigay discrimination from this experiment should be, if anything, conservative (see Pager [2003, pp. 95051] for analogous control strategies in another audit study). Furthermore, if the socialist/ progressive applicant is seen as more leftist than the gay applicant, he may be subject to political discrimination in politically conservative areas. In that case, this study would produce conservative estimates of sexual orientation discrimination in the South and the Midwest. If there were such an effect, it would lend even more confidence to my findings about regional variation (see the "Findings" section).

${ }^{7}$ One concern about the use of recruitment websites was the possibility of a very low response rate due to the large number of applications. I took several steps to overcome this problem. First, I restricted the sample to job postings whose requirements matched the profile of my fictitious applicants (graduating college student with little or no full-time work experience). Second, based on the experience of pretests, I used cover letters to indicate the applicants' desire to relocate to the target location (see $n$. 10). Third, I responded to newly posted ads as soon as possible. In addition, this audit was conducted in 2005, a year with relatively high job growth (http://www.data.bls.gov), so individual employers may have received somewhat fewer applications than in years with higher unemployment. An additional concern was the appearance of identical ads (i.e., by the same employer, in the same location, for the same position) on more than one website. In such cases, only one résumé pair was sent in response.
} 
Before sending out each résumé pair, I randomly assigned the gay signal to one of the résumés and the control signal to the other résumé. Thus, even though the résumés differed from each other in order to avoid raising suspicion, there was no systematic relationship between résumé quality and sexual orientation. Consequently, any significant difference in callback rates could be attributed to the experimental manipulation of the résumés. ${ }^{8}$ Importantly, I varied only the name of the treatment organization and the control organization on the résumés (fig. A1). As a result, the activities of the applicants in their respective groups were not systematically related to sexual orientation. Thus, I effectively controlled for any differences in the applicants' achievements in the treatment organization and the control organization. ${ }^{9}$ In sum, sexual orientation was randomly assigned with respect to both overall résumé quality and the quality of experiences within the control and treatment organizations.

The treatment/control signal appeared at the end of the "experience" section of the résumé and was just one of several experiences described in that section. ${ }^{10}$ In addition to the résumés, I created corresponding cover letters that briefly stated the applicant's desire to work in the targeted position and his desire to move to the city or town where the employer was located. ${ }^{11}$ For each application, I recorded whether it led to an in-

\footnotetext{
${ }^{8}$ This design ensured that the gay signal was sometimes attached to "résumé A" and sometimes to "résumé B." I used logistic regression analysis to check whether randomization had indeed occurred and found no systematic relationship between treatment assignment and a dummy variable indicating which of the two résumés (A or B) was used. In addition, I found that résumés $\mathrm{A}$ and $\mathrm{B}$ did not differ significantly in the number of callbacks they generated either in the overall sample or in the subsamples of gay and heterosexual applicants or in subsamples by state.

${ }^{9}$ For the sake of brevity, I refer to fictitious applicants who were assigned the control signal as "heterosexual." More precisely, these applicants would be described as "fictitious job seekers who did not give evidence of being gay" (see Correll et al. 2007).

${ }^{10}$ Since this study focused on sexual orientation discrimination, I held the race of the fictitious applicants constant. Thus, the résumés did not mention any involvement in race- or ethnicity-related organizations (e.g., "Black Students Association"), and the fictitious applicants' names were made up of common first and last names that would not send a strong and salient signal of being from a particular racial minority group ("David Miller" and "Michael Williams").

${ }^{11}$ The cover letters corresponding to the two résumés were similar in style and content and made no mention of the applicants' involvement in either the gay or the progressive/socialist group. Because of the random assignment of the gay signal to the résumés, there was no systematic relationship between the quality of the cover letter and the sexual orientation of the applicant. The cover letter explained that the motivation for moving to the target city included family reasons and that the applicant was originally from the targeted area, with many of his family members still living there. Pretests indicated that including such a statement would be useful in increasing the overall response rate and simplifying the experimental protocol. During early pretests that did not include a statement about relocation, the response rate was very low, and several employers responded by simply directing the applicant to a branch that was geographically closer to the applicant's college.
} 
vitation to a first-round job interview (either an in-person or a telephone interview). To receive employer responses, I set up e-mail accounts with a web-based e-mail service as well as voice mail boxes with an inexpensive Voice-over-Internet-Protocol service.

The Sample of Jobs

I submitted a total of 3,538 résumés, responding to 1,769 job postings by private employers. The size of this sample was comparable to that in previous large-scale correspondence audits (Weichselbaumer 2003; Bertrand and Mullainathan 2004; Correll et al. 2007; Drydakis 2009). In addition, statistical power analysis (Cohen 1969) indicated that this sample size provided more than sufficient statistical power to detect even relatively small differences in callback rates by sexual orientation. The sample included jobs in five occupations and seven states. Limiting the sample in this way ensured that a sufficient number of observations were available in each state and occupation to make meaningful comparisons. The five occupations in the sample were managers, business and financial analysts, sales representatives, customer service representatives, and administrative assistants. The sampled states included four states in the Northeast and the West (New York, Pennsylvania, California, Nevada) and three states in the Midwest and the South (Ohio, Florida, Texas), all with a relatively high number of job postings on the recruitment websites I used. The number of job postings in a state ranged from 131 (Nevada) to 347 (Florida), with at least 200 observations in each state other than Nevada. Statistical power research (Cohen 1969) suggested that the size of these subsamples would provide adequate statistical power for detecting even relatively modest differences in the proportion of callbacks between gay and nongay applicants in each state.

It is important to note that the sampled states varied, both in level of tolerance toward gay people and in having or lacking laws regarding sexual orientation discrimination (Lax and Phillips 2009). Indeed, these states-and the counties and cities within them-offered an intriguing mosaic of different legal environments. While California, Nevada, and New York prohibit sexual orientation discrimination in private employment, the other four states have no such legislation. At the same time, with the exception of Nevada, each state has some cities and counties that ban sexual orientation discrimination. Thus, the sample contained employers in a variety of legal environments, ranging from employers who were not subject to any antidiscrimination law protecting gay men to employers who were simultaneously subject to state, county-, and city-level antidiscrimination laws. Table 1 displays antidiscrimination laws in the sampled states. Table 2 presents the distribution of sampled jobs by state and by occupation. 
TABLE 1

ANTIDISCRIMINATION LAWS IN THE SAMPLED States AT THE TIME OF THE EXPERIMENT

\begin{tabular}{ccl}
\hline \hline State & $\begin{array}{c}\text { State Prohibits Sexual } \\
\text { Discrimination by } \\
\text { Private Employers }\end{array}$ & \multicolumn{1}{c}{$\begin{array}{c}\text { Examples of Cities/Counties } \\
\text { With Sexual Orientation } \\
\text { Discrimination Ban }\end{array}$} \\
\hline California $\ldots \ldots$. & Yes & Los Angeles, San Francisco \\
Nevada ....... & Yes & None \\
New York ..... & Yes & Albany, Buffalo, New York City \\
Pennsylvania .. & No & Philadelphia, Pittsburgh \\
Ohio .......... & No & Toledo \\
Florida $\ldots . . . .$. & No & Miami-Dade County, Monroe County \\
Texas $\ldots \ldots \ldots \ldots$ & No & Austin, Dallas, El Paso \\
\hline
\end{tabular}

Variables

The dependent variable (positive response) was a dummy indicating whether the application elicited an invitation to an interview. The main independent variable (gay) was a dummy indicating whether the résumé listed involvement in the gay campus organization. To examine variation in the level of discrimination across states, I created dummy variables to represent each state in the sample. To ascertain whether an employer was subject to a relevant antidiscrimination law protecting gay employees, I used a list of laws compiled by Lambda Legal (2005). The resulting dummy variables were denoted city law, county law, and state law.

Unfortunately, there is no representative and reliable data about attitudes toward homosexuality at the city and county levels, and such data is scarce even at the state level. To overcome these data limitations, Lax and Phillips (2009) used national surveys and recent advances in multilevel modeling to estimate state-level public opinion about different gay

TABLE 2

Sampled Jobs by State AND By OCCuPation

\begin{tabular}{|c|c|c|c|c|c|c|}
\hline State & $\begin{array}{l}\text { Adminis- } \\
\text { trative } \\
\text { Assistant }\end{array}$ & Analyst & $\begin{array}{l}\text { Customer } \\
\text { Service } \\
\text { Represen- } \\
\text { tative }\end{array}$ & Manager & $\begin{array}{l}\text { Sales } \\
\text { Represen- } \\
\text { tative }\end{array}$ & $\begin{array}{l}\text { Total } \\
\text { in } \\
\text { State }\end{array}$ \\
\hline California ........... & 90 & 36 & 66 & 52 & 93 & 337 \\
\hline Florida $\ldots \ldots \ldots \ldots$ & 81 & 39 & 68 & 78 & 81 & 347 \\
\hline Nevada $\ldots \ldots \ldots \ldots$ & 41 & 13 & 31 & 20 & 26 & 131 \\
\hline New York .......... & 81 & 28 & 41 & 38 & 48 & 236 \\
\hline Ohio $\ldots \ldots \ldots \ldots \ldots$ & 60 & 28 & 35 & 64 & 32 & 219 \\
\hline Pennsylvania $\ldots \ldots \ldots$ & 63 & 28 & 34 & 33 & 43 & 201 \\
\hline Texas ............... & 84 & 34 & 61 & 52 & 67 & 298 \\
\hline Total in occupation & 500 & 206 & 336 & 337 & 390 & 1,769 \\
\hline
\end{tabular}


rights policies. This estimation yielded measures of state-level public support for policies like same-sex marriage, civil unions, hate crimes laws, and antidiscrimination laws in employment. In this study, to capture public attitudes toward gay employees (state-level attitude), I used the estimated state-level percentage of the population who support an employment nondiscrimination law protecting gay people.

To identify stereotypically male heterosexual traits required of the job applicants, I searched the job postings for word roots and variants of the 20 masculine characteristics listed in the Bem Sex Role Inventory (1974), a widely used psychological instrument (see also Madon 1997; Gorman 2005). The most frequently mentioned masculine characteristics in the job ads were (1) decisiveness (e.g., "makes decisions independently," "a decisive, resultsoriented manager"), (2) assertiveness and aggressiveness (e.g., "assertive personality," "aggressive self-starter"), and (3) ambition (e.g., "an ambitious college graduate"). Following Weichselbaumer (2004), I recorded whether each job posting described the ideal job candidate as aggressive or assertive, decisive, or ambitious. ${ }^{12}$ Using these codes, I created three dummy variables: (1) $d e-$ cisive, (2) aggressive or assertive, and (3) ambitious.

In addition, to examine the possibility that positive stereotypes of gay men reduce the likelihood of discrimination, I searched the job postings for stereotypically gay male positive characteristics identified by Morrison and Bearden (2007). Only one such characteristic appeared with some frequency: articulateness (sometimes described broadly as "communication skills"; e.g., "must be articulate," "exceptional verbal communication skills"). Thus, I created a dummy variable to indicate whether the posting mentioned the importance of such skills (communication skills). Finally, although the main analyses focused on the above-described factors, it was necessary to control for several other variables that may affect the likelihood of discrimination. These controls included job, employer, and area characteristics. Table 3 lists these variables.

\footnotetext{
${ }^{12}$ The coding was performed manually with the help of a trained research assistant to ensure that only phrases related to the description of the ideal job candidate were coded (e.g., a phrase like "a bright, ambitious graduate" would be coded as "ambitious" but the phrase "an ambitious start-up firm" would not be.)
} 
TABLE 3

Control VARIables

\begin{tabular}{ll}
\hline \hline Variable & \multicolumn{1}{c}{ Definition and Data Source } \\
\hline Industry wage & Annual median wage in the employer's \\
& North American Industry Classification \\
& System (NAICS) sector code in 2004, ob- \\
tained from the website of the Bureau of \\
Labor Statistics (http://www.bls.gov). The \\
employer's NAICS code was identified \\
with the company databases ICARUS and \\
Onesource Business Browser. \\
Total number of employees, in thousands, \\
obtained from the company databases \\
ICARUS and Onesource Business \\
Browser. \\
The percentage of men in the occupation, \\
obtained from the Bureau of Labor Sta- \\
tistics (2009). The five occupational cate- \\
gories were customer service representa- \\
tives, sales representatives (in all \\
sectors), administrative assistants (in- \\
cluding secretaries), managers (all "man- \\
agement occupations"), and analysts (in- \\
cluding management, \\
financial, and budget analysts). \\
Dummy variable = 1 if, according to the job \\
posting, the position explicitly required an \\
ability to work as part of a team. \\
The percentage of the population classified as \\
urban in the 2000 U.S. Census. Measured \\
at the zip code level in the main analyses; \\
all models were also reestimated with ur- \\
banness measured at the county and cen- \\
sus tract levels, and the results remained \\
stable under these specifications. \\
The percentage of the local population \\
ages 25 years or older with at least a \\
bachelor's degree; obtained from the \\
2000 U.S. Census. Measured at the zip \\
code level in the main analyses; all mod- \\
els were also reestimated with urbanness \\
measured at the county and census tract \\
levels, and the results remained stable \\
under these specifications. \\
The county-level percentage of Republican \\
votes in the 2004 presidential election, \\
obtained from CNN (http://www.cnn \\
com/ELECTION/2004). \\
The unemployment rate in the county, ob- \\
tained from the website of the Bureau \\
of Labor Statistics (http://www.bls.gov). \\
\hline Education
\end{tabular}


Openly Gay Men and Employment Discrimination

TABLE 4

Descriptive Statistics

\begin{tabular}{|c|c|c|c|c|}
\hline Variable & Mean & $\mathrm{SD}$ & Minimum & Maximum \\
\hline \multicolumn{5}{|l|}{ States: } \\
\hline California & .19 & .39 & 0 & 1 \\
\hline Florida $\ldots$ & .20 & .40 & 0 & 1 \\
\hline New York $\ldots \ldots \ldots \ldots \ldots$ & .13 & .34 & 0 & 1 \\
\hline Nevada $\ldots \ldots \ldots \ldots \ldots \ldots$ & .07 & .26 & 0 & 1 \\
\hline Ohio $\ldots \ldots \ldots+\ldots \ldots \ldots$ & .12 & .33 & 0 & 1 \\
\hline Pennsylvania $\ldots \ldots \ldots \ldots$ & .11 & .32 & 0 & 1 \\
\hline Texas $\ldots \ldots \ldots \ldots \ldots \ldots$ & .17 & .37 & 0 & 1 \\
\hline \multicolumn{5}{|l|}{ Laws and attitudes: } \\
\hline City law $\ldots \ldots \ldots \ldots \ldots$ & .24 & .42 & 0 & 1 \\
\hline County law $\ldots \ldots \ldots \ldots$ & .10 & .30 & 0 & 1 \\
\hline State law $\ldots \ldots \ldots \ldots \ldots$ & .40 & .49 & 0 & 1 \\
\hline State-level attitude $\ldots . .$. & 65.4 & 2.84 & 61 & 70 \\
\hline \multicolumn{5}{|l|}{ Required traits and skills: } \\
\hline Aggressive or assertive & .07 & .25 & 0 & 1 \\
\hline Decisive $\ldots \ldots \ldots \ldots \ldots \ldots$ & .15 & .35 & 0 & 1 \\
\hline Ambitious $\ldots \ldots \ldots \ldots \ldots$ & .09 & .28 & 0 & 1 \\
\hline Communication skills $\ldots$ & .46 & .49 & 0 & 1 \\
\hline \multicolumn{5}{|l|}{ Controls: } \\
\hline Industry wage* & 40.67 & 10.11 & 18.94 & 58 \\
\hline Employer size $\dagger \ldots \ldots \ldots$. & 1.85 & 11.77 & .003 & 289 \\
\hline Percentage of males ..... & 32.11 & 22.64 & 8.7 & 61.4 \\
\hline Teamwork .............. & .11 & .31 & 0 & 1 \\
\hline Education $\ldots \ldots \ldots \ldots$ & 30.46 & 18.93 & 2.16 & 83.02 \\
\hline Urbanness $\ldots \ldots \ldots \ldots \ldots$ & 93.9 & 16.52 & 0 & 100 \\
\hline Unemployment $\ldots \ldots \ldots$. & 5.04 & 1.00 & 3.1 & 15 \\
\hline
\end{tabular}

* In thousands of U.S. dollars.

$\dagger$ In thousands of employees.

\section{FINDINGS}

\section{Descriptive Overview}

The submission of résumés led to a total of 331 interview invitations, an overall callback rate of $9.35 \% .{ }^{13}$ Table 4 displays descriptive statistics. Table 5 tabulates callback rates by sexual orientation. The first row in table 5 presents the results for the full data set. While heterosexual applicants had an $11.5 \%$ chance of being invited for an interview, equally qualified gay applicants only had a $7.2 \%$ chance of receiving a positive response. This is a difference of 4.3 percentage points, or about $40 \%$. This gap is statistically significant $(P<.001)$ and implies that a heterosexual

${ }^{13}$ This response rate is similar to that in recent correspondence studies (e.g., Bertrand and Mullainathan 2004). Neither the overall response rate nor the response rate for gay vs. heterosexual applicants varied significantly by the month when the application was submitted. 
TABLE 5

Callback Rates By Sexual Orientation

\begin{tabular}{|c|c|c|c|c|}
\hline \multirow[b]{2}{*}{ SAMPLE ( $n$ Job Ads) } & \multicolumn{2}{|c|}{ \% CALlBaCK } & \multirow[b]{2}{*}{ RATIO } & \multirow{2}{*}{$\begin{array}{l}\text { DIFFERENCE } \\
(P \text {-value })\end{array}$} \\
\hline & Not Gay & Gay & & \\
\hline Total sample $(n=1,769)$ & 11.5 & 7.2 & 1.59 & $4.3(.000)$ \\
\hline California $(n=337) \ldots$ & 11.0 & 9.2 & 1.20 & $1.8(.443)$ \\
\hline Nevada $(n=131) \ldots$ & 12.2 & 6.1 & 2.00 & $6.1(.087)$ \\
\hline New York $(n=236)$. & 10.2 & 11.4 & .89 & $-1.2(.656)$ \\
\hline Pennsylvania $(n=201) \ldots \ldots \ldots \ldots$ & 12.9 & 9.4 & 1.37 & $3.5(.268)$ \\
\hline Ohio $(n=219) \quad \ldots \ldots \ldots \ldots \ldots \ldots \ldots \ldots$ & 14.1 & 5.5 & 2.56 & $8.6(.002)$ \\
\hline Florida $(n=347)$ & 9.5 & 5.5 & 2.11 & $4.0(.044)$ \\
\hline Texas $(n=298)$ & 12.0 & 3.7 & 3.24 & $8.3(.000)$ \\
\hline \multicolumn{5}{|l|}{$\begin{array}{l}\text { Employers subject to a city, county, or } \\
\text { state law that prohibits sexual } \\
\text { orientation discrimination: }\end{array}$} \\
\hline Yes $(n=983) \ldots \ldots \ldots \ldots \ldots \ldots \ldots \ldots$ & 11.6 & 8.7 & 1.33 & $2.9(.037)$ \\
\hline No $(n=786) \quad \ldots \ldots \ldots \ldots \ldots \ldots \ldots \ldots \ldots$ & 11.3 & 5.3 & 2.13 & $6.0(.000)$ \\
\hline \multicolumn{5}{|l|}{$\begin{array}{l}\text { Job postings that require stereotypically } \\
\text { male heterosexual traits:* }\end{array}$} \\
\hline Yes $(n=475) \ldots \ldots \ldots \ldots \ldots \ldots \ldots \ldots \ldots \ldots \ldots$ & 13.5 & 4.8 & 2.81 & $8.7(.000)$ \\
\hline No $(n=1,294)$ & 10.7 & 8.1 & 1.32 & $2.5(.0226)$ \\
\hline
\end{tabular}

* Assertiveness/aggressiveness, decisiveness, or ambition.

job seeker had to apply to fewer than nine different jobs to receive a positive response, while a gay applicant needed to reply to almost 14 ads to achieve the same result. The magnitude of this difference is comparable to the gap in callback rates between black and white job seekers in Boston and Chicago (Bertrand and Mullainathan 2004).

The size of the callback gap, however, varied substantially across states. On the one hand, in the southern and midwestern states in the sample (Texas, Florida, and Ohio), there was a substantial difference in the callback rates of gay and heterosexual applicants. In Texas and Ohio, for example, the size of the callback gap (8.3 and 8.6 percentage points, respectively) was substantially larger than in the overall sample (4.1 percentage points). By contrast, there was no statistically significant callback gap in any of the western and northeastern states (California, Nevada, Pennsylvania, and New York). The size of the gap, however, showed some intraregional variation as well. In California, for example, the difference in callback rates was less than 2 percentage points and was clearly insignificant statistically. In neighboring Nevada, by contrast, the gap was nearly significant at the standard level $(P=.087)$.

Similarly, there was variation in the callback gap across legal environments. In the case of employers subject to a relevant antidiscrimination law, either at the city-, county-, or state-level, the callback gap was less 
than 3 percentage points; in the case of employers not subject to such regulation, the gap was as large as 6 percentage points. In both cases, however, the callback gap was statistically significant. In addition, as expected, the callback gap was particularly large in the case of employers who emphasized the importance of stereotypically male heterosexual traits. Notably, however, there was a statistically significant callback gap even within the sample of employers who did not specifically require such traits.

\section{The Net Effect of Discrimination}

To examine whether the above findings are robust to the inclusion of control variables, I now turn to regression analysis. Table 6 presents the results of a logistic regression predicting a positive employer response. Coefficients are expressed as odds ratios. Thus, a coefficient greater than one indicates that the variable in question was positively associated with receiving a callback, while a coefficient less than one indicates a negative association. This model shows that listing involvement in a gay campus organization had a significant negative effect on the success of applicants even when controlling for numerous job-related and area characteristics. ${ }^{14}$ The odds ratio of gay (0.6) can be interpreted as the net multiplicative impact of the gay signal on the odds of receiving a callback. What does this mean in terms of probabilities? Consider, for example, a situation where a heterosexual applicant had a $10 \%$ chance of receiving a positive response for a given job (i.e., the odds of getting a callback is $0.1 / 0.9=$ 0.111). Then, the predicted odds of a callback for an equally qualified gay applicant for a comparable job would have been 0.067 (i.e., $0.6 \times$ 0.111 ) - a probability of only $6.3 \%$. This result confirms that, on average, an openly gay applicant would have to search substantially longer than an equally qualified heterosexual applicant before receiving a callback from an employer.

\section{Regional Variation}

To explore the conditions that influence the level of discrimination, the models in table 7 include interaction terms between sexual orientation and several other factors. In these models, the main variables of interest

\footnotetext{
${ }^{14}$ The $R^{2}$ is low in this model, as well as in the other models, because the purpose of this experiment was not the identification of all the variables that predict a positive employer response (in which case, I would have experimentally manipulated a different set of factors, particularly the applicants' qualifications and skills). Rather, the goal here was to examine whether one randomly assigned variable (gay) had an effect on callbacks.
} 
TABLE 6

OdDS RATIOS FOR THE LOGISTIC REgRESSION

Predicting Employer Callback

\begin{tabular}{|c|c|c|}
\hline Model 1 & Odds Ratio & SE \\
\hline Gay & $.60^{* * * *}$ & .07 \\
\hline New York $\ldots \ldots \ldots \ldots \ldots$ & .80 & .21 \\
\hline Pennsylvania $\quad \ldots \ldots \ldots \ldots \ldots$ & 1.20 & .29 \\
\hline Nevada $\ldots \ldots \ldots \ldots \ldots \ldots$ & .80 & .24 \\
\hline California $\ldots \ldots \ldots \ldots \ldots$ & 1.16 & .24 \\
\hline Florida $\ldots \ldots \ldots \ldots \ldots \ldots$ & .71 & .18 \\
\hline Ohio $\ldots \ldots \ldots \ldots \ldots \ldots \ldots \ldots$ & 1.35 & .32 \\
\hline Assertive or aggressive $\ldots .$. & .85 & .21 \\
\hline Decisive $\ldots \ldots \ldots \ldots \ldots \ldots \ldots$ & .87 & .15 \\
\hline Ambitious $\ldots \ldots \ldots \ldots \ldots \ldots$ & 1.37 & .28 \\
\hline Communication skills ...... & 1.06 & .13 \\
\hline Administrative assistant ... & .95 & .16 \\
\hline Sales representative $\ldots \ldots \ldots$ & 1.11 & .20 \\
\hline Analyst $\ldots \ldots \ldots \ldots \ldots \ldots$ & $.60^{*}$ & .14 \\
\hline Manager $\ldots \ldots \ldots \ldots \ldots \ldots$ & $.61^{*}$ & .13 \\
\hline Employer size $\ldots \ldots \ldots \ldots \ldots$ & 1.00 & .004 \\
\hline Industry wage $\ldots \ldots \ldots \ldots$ & .99 & .006 \\
\hline Teamwork $\ldots \ldots \ldots \ldots \ldots$ & 1.42 & .27 \\
\hline Unemployment $\ldots \ldots \ldots \ldots$ & .85 & .07 \\
\hline Urbanness ................. & 1.00 & .004 \\
\hline Education $\ldots \ldots \ldots \ldots \ldots \ldots$ & 1.00 & .003 \\
\hline Conservative voters ........ & $.99^{* *}$ & .004 \\
\hline City law $\ldots \ldots \ldots \ldots \ldots \ldots$ & 1.12 & .17 \\
\hline County law $\ldots \ldots \ldots \ldots \ldots$ & .871 & .871 \\
\hline McFadden's pseudo $R^{2} \ldots$ & .029 & \\
\hline Baseline odds $^{\mathrm{a}} \ldots \ldots \ldots \ldots$ & .130 & \\
\hline
\end{tabular}

Note. $-N=3,538$. Since coefficients are expressed as odds ratios, coefficients $<1$ indicate a negative relationship. SEs are robust and corrected for clustering on job ad because the data contain two records per ad. Dummies for Texas and customer service representative are omitted.

${ }^{\text {a }}$ Predicted odds of callback for nongay applicant in case of a hypothetical job that is in each of the reference categories for dummy variables and is at the average of each continuous variable. Thus, in this case, the baseline odds represent the predicted odds of a nongay candidate applying for a Texas customer service job (located in a city and county without relevant antidiscrimination laws) that does not explicitly require any of the skills and traits included in this model and is average in all the continuous control variables (e.g., industry wage and employer size).

$$
\begin{aligned}
& { }^{*} P<.05 . \\
& { }^{* * *} P<.01 . \\
& { }^{* * *} P<.001
\end{aligned}
$$


TABLE 7

Odds Ratios for the Logistic Regression Predicting Employer Callback

\begin{tabular}{|c|c|c|c|c|c|c|}
\hline & \multicolumn{2}{|c|}{ Model 2} & \multicolumn{2}{|c|}{ MODEL 3} & \multicolumn{2}{|c|}{ Model 4} \\
\hline & Coeff. & $\mathrm{SE}$ & Coeff. & SE & Coeff. & SE \\
\hline \multicolumn{7}{|l|}{ Interaction terms: } \\
\hline \multicolumn{7}{|l|}{ States: } \\
\hline Gay $\times$ New York .... & $4.03 * *$ & 1.84 & & & & \\
\hline Gay $\times$ Pennsylvania $\ldots . . .$. & $2.50 *$ & 1.15 & & & & \\
\hline Gay $\times$ California $\ldots \ldots \ldots \ldots \ldots$ & $2.99 * *$ & 1.29 & & & & \\
\hline Gay $\times$ Ohio $\ldots \ldots \ldots \ldots \ldots \ldots$ & 1.48 & .72 & & & & \\
\hline Gay $\times$ Nevada $\ldots \ldots \ldots \ldots \ldots$ & 1.67 & .95 & & & & \\
\hline Gay $\times$ Florida $\ldots \ldots \ldots \ldots \ldots$ & 2.01 & .91 & & & & \\
\hline \multicolumn{7}{|l|}{ Laws and attitudes: } \\
\hline Gay $\times$ city law $\ldots \ldots$ & & & 1.02 & .28 & .85 & .24 \\
\hline Gay $\times$ county law $\ldots \ldots \ldots \ldots$ & & & $2.45^{*}$ & 1.00 & 2.14 & .89 \\
\hline Gay $\times$ state law $\ldots \ldots \ldots \ldots \ldots$ & & & $1.82 *$ & .45 & .87 & .36 \\
\hline Gay $\times$ state-level attitude $\ldots \ldots \ldots$ & & & & & $1.17 *$ & .09 \\
\hline \multicolumn{7}{|l|}{ Required traits and skills: } \\
\hline Gay $\times$ assertive or aggressive & $.28 *$ & .18 & $.28 *$ & .18 & $.28^{*}$ & .18 \\
\hline Gay $\times$ decisive $\ldots \ldots \ldots \ldots \ldots$ & $.47 *$ & .17 & $.45 *$ & .16 & $.46^{*}(.17)$ & .17 \\
\hline Gay $\times$ ambitious $\ldots \ldots \ldots \ldots \ldots$ & .68 & .26 & .69 & .27 & .67 & .26 \\
\hline Gay $\times$ communication skills $\ldots$ & .87 & .20 & .89 & .22 & .88 & .20 \\
\hline \multicolumn{7}{|l|}{ Main effects: } \\
\hline Gay $\ldots \ldots \ldots \ldots \ldots \ldots \ldots \ldots \ldots$ & $.33 * *$ & .12 & $.52 * *$ & .10 & $.00002 * *$ & .00007 \\
\hline New York $\ldots \ldots \ldots \ldots \ldots \ldots \ldots$ & $.47^{*}$ & .15 & & & & \\
\hline Pennsylvania $\ldots \ldots \ldots \ldots \ldots \ldots \ldots$ & .89 & .25 & & & & \\
\hline California $\ldots \ldots \ldots \ldots \ldots \ldots \ldots \ldots$ & .83 & .21 & & & & \\
\hline Ohio $\ldots \ldots \ldots \ldots \ldots \ldots \ldots \ldots$ & 1.15 & .32 & & & & \\
\hline Nevada $\ldots \ldots \ldots \ldots \ldots \ldots \ldots \ldots$ & .71 & .25 & & & & \\
\hline Florida $\ldots \ldots \ldots \ldots \ldots \ldots \ldots \ldots$ & $.57 *$ & .16 & & & & \\
\hline City law $\ldots \ldots \ldots \ldots \ldots \ldots \ldots$ & & & 1.11 & .22 & 1.18 & .24 \\
\hline County law $\ldots \ldots \ldots \ldots \ldots \ldots \ldots$ & & & $.48 *$ & .15 & $.50 *$ & .16 \\
\hline State law $\ldots \ldots \ldots \ldots \ldots \ldots \ldots$ & & & .81 & .14 & .98 & .26 \\
\hline State-level attitude ............... & & & & & .96 & .04 \\
\hline Assertive or aggressive $\ldots . . . \ldots \ldots$ & 1.20 & .34 & 1.20 & .34 & 1.20 & .34 \\
\hline Decisive $\ldots \ldots \ldots \ldots \ldots \ldots \ldots$ & 1.14 & .23 & 1.20 & .24 & 1.19 & .24 \\
\hline Ambitious $\ldots \ldots \ldots \ldots \ldots \ldots \ldots$ & 1.57 & .38 & 1.53 & .37 & 1.55 & .37 \\
\hline Communication skills $\ldots \ldots \ldots \ldots$ & 1.10 & .17 & 1.09 & .17 & 1.10 & .18 \\
\hline McFadden's pseudo $R^{2} \ldots \ldots \ldots \ldots$ & .033 & & .029 & & .031 & \\
\hline Baseline odds ${ }^{\mathrm{a}} \ldots \ldots \ldots \ldots \ldots \ldots \ldots$ & .154 & & .129 & & .119 & \\
\hline
\end{tabular}

Note. $-N=3,538$. All models included controls for employer size, percentage of males in occupation, industry wage, teamwork, urbanness, education, unemployment, and conservative voters; the coefficients for these variables are omitted to conserve space. Robust SEs (in parentheses) are corrected for clustering on job ad because the data contain two records per ad. The Texas dummy is omitted.

${ }^{\text {a }}$ Predicted odds of callback for nongay applicant in case of a hypothetical job that is in each of the reference categories for dummy variables and is at the average of each continuous variable. For example, in model 2, the baseline odds represent the predicted odds of a nongay candidate applying for a Texas job that does not explicitly require any of the skills and traits included in this model and is at average in all the continuous control variables (e.g., industry wage and employer size).

$$
\begin{aligned}
& * P<.05 . \\
& * * P<.01 .
\end{aligned}
$$


are the interaction terms.$^{15}$ Model 2 indicates significant variation in the level of discrimination across regions even after controlling for other factors. Compared to employers in Texas, firms in New York, Pennsylvania, and California were significantly less likely to treat gay job applicants unfavorably. In the other three states (Florida, Ohio, and Nevada), the level of discrimination was not significantly different from that in Texas. To understand the magnitude of these regional differences, consider the example of a gay applicant who has a $3.7 \%$ probability (or odds of 0.038 ) of receiving a callback for a given job in Texas-the average probability of success for gay applicants in that state. If this job seeker applied for a similar job in California, he would be predicted to have a $10.2 \%$ chance (or odds of 0.114) for a callback.

In models not reported here, I used industry and occupation dummies to control for industry- and occupation-specific factors while examining regional variation. The observed regional variation remained significant. Indeed, an analysis of interaction terms between gay and occupational categories, and between gay and industry categories, revealed that the likelihood of discrimination did not vary significantly across occupations and industries. Thus, the possible over- or underrepresentation of certain occupations or industries in a region could not account for the geographic variation documented in this study.

What explains, then, the observed regional variation? One hypothesis might be that regional differences reflect variation in the adoption of laws protecting gay men from discrimination. Model 3 lends some credit to this hypothesis. The coefficients of the interaction terms gay $\times$ county law and gay $\times$ state law are significant and greater than one, suggesting that employers located in states and counties with a relevant antidiscrimination law were less likely to discriminate against gay applicants. This result, however, does not necessarily imply that lower levels of discrimination were due entirely to antidiscrimination laws. Since public opinion toward gay people might affect both the level of discrimination and the probability that an antidiscrimination policy is adopted, the effect of laws on discrimination may be confounded with the effect of attitudes (Klawitter and Flatt 1998).

To fully untangle the effects of laws and attitudes, we would need reliable data about within-state variation in attitudes toward gay men. Such data, however, are currently not available. Thus, model 4 represents just a first and very preliminary step in exploring the relationship between laws, attitudes, and discrimination. This model differs from model 3 in

\footnotetext{
${ }^{15}$ Since these models include interaction terms, the low-order coefficients of variables included in interaction terms (such as the variable gay) cannot be interpreted as if they were ordinary coefficients in a model with no interactions.
} 
that it includes a measure of state-level public support for gay employment rights. This variable seems to have a significant negative association with discrimination, and once it is included in the model, the independent effects of antidiscrimination laws disappear. This finding, however, should be interpreted with great caution. Most important, given the small number of states in the sample, it is difficult to distinguish the impact of statelevel variables from the effects of the specific states themselves. Moreover, the relationship between antidiscrimination laws, attitudes, and discrimination is likely too complex to be captured in a cross-sectional analysis with a small number of states. As noted above, social acceptance of gay people might make the adoption of antidiscrimination laws more likely, but antidiscrimination laws might also have an effect on social attitudes (Klawitter and Flatt 1998), and both laws and attitudes may affect the likelihood of discrimination. Thus, precisely untangling the effects of laws and attitudes remains a task for future research.

In addition, model 3 raises another question about the mechanisms at work. By what mechanism might local (in this case, county-level) antidiscrimination laws affect employer behavior in states that prohibit discrimination on the basis of sexual orientation? In other words, what explains the negative association between the extent of discrimination and the presence of county-level laws once the relevant state-level laws are held constant? Two mechanisms may help explain this finding. First, county laws might reflect more tolerant local attitudes, which-as noted above-we cannot directly measure at this time. Second, although local ordinances tend to be less powerful than state laws, they may provide some additional protection and oversight, often by mandating a local commission to investigate complaints of discrimination (e.g., Cook County Commission on Human Rights 2003). Future research might explore these mechanisms in more depth.

\section{Required Personality Traits}

In all three models in table 7 , the interaction terms gay $\times$ aggressive or assertive and gay $\times$ decisive have significant coefficients and imply that employers who emphasized the importance of aggressiveness, assertiveness, or decisiveness were particularly likely to discriminate against gay applicants. For example, consider a situation where a gay applicant has a $10 \%$ probability (or odds of 0.111 ) of receiving a callback from an employer that does not explicitly seek aggressive or assertive employees. If this applicant applied for an otherwise comparable job with an explicit requirement of aggressiveness or assertiveness, his predicted chance of success would only be $3 \%$ (or odds of 0.031). This finding is consistent 
with the hypothesis that stereotypes play an important role in discrimination against gay men. ${ }^{16}$

Not all discrimination, however, was attributable to the potential effect of stereotyping. Clearly, as table 5 indicates above, there was a significant callback gap even in the case of job postings that did not emphasize stereotypically male heterosexual traits. Indeed, when I estimated the logistic regression in table 6 on the subsample of jobs that did not require assertiveness, aggressiveness, or decisiveness, the odds-ratio coefficient of the variable gay remained significant $(P<.01)$ and less than one $(0.70)$. Thus, even when these traits were not emphasized, gay applicants suffered significant callback discrimination.

At the same time, the coefficient of the interaction term gay $\times$ ambitious is insignificant in all models. Thus, the level of discrimination did not differ between employers who emphasized the importance of ambition and those who did not. One interpretation of this finding might be that, although ambition is a stereotypically masculine trait (Bem 1974), gay men are more strongly stereotyped as lacking traits like assertiveness and aggressiveness than as lacking ambition (Madon 1997). In addition, the coefficient of the gay $\times$ communication skills interaction was also insignificant in all models, suggesting that gay applicants enjoyed no advantage when responding to ads that emphasized communication skills. Thus, it seems that stereotypes mainly hurt, rather than helped, gay job seekers. Finally, in unreported models, I used three-way interactions (gay $\times$ state $x$ required trait) to examine whether the effects of required personality traits varied across states; however, I found no significant evidence for such variation.

\section{Robustness Checks}

I performed several analyses to examine the robustness of the above findings to alternative model specifications. First, in alternative versions of all the above models, I used cluster-adjusted standard errors to take into account the potential correlation of residuals within a state. Second, I replaced percentage of males and industry wage with occupation and industry dummies (in both the main and the interaction terms) to check for the effect of occupation- and industry-specific factors that might not be captured in the main models. Third, I used dummy variables and corresponding interaction terms to control for any potential effect of the

\footnotetext{
${ }^{16}$ This result was consistent across regions; in models not reported here, I used interaction terms (e.g., gay $\times$ decisive $\times$ Texas) to examine whether the extent to which the required personality traits made discrimination more likely varied across states, but I found no variation.
} 
three recruitment websites on which the job postings appeared. Fourth, I included controls for clustering by employers who posted multiple jobs. The coefficient estimates of interest remained stable under all these specifications, indicating discrimination overall, as well as variation in the level of discrimination by region and by the traits required in the job postings.

\section{DISCUSSION}

During the past decade, the labor market disadvantages of LGBT employees in the United States have been subject to intense political debates and have received increasing attention from social scientists (Badgett et al. 2007). To date, however, researchers have provided little direct evidence about the inequalities that LGBT Americans might face in obtaining a job. This is a significant lacuna because discrimination in hiring is a crucial inequality-generating mechanism that regulates job seekers' access to the broader array of labor market opportunities (Pager 2007). Indeed, hiring discrimination is a relatively understudied area in the wider labor market literature (Petersen and Saporta 2004). To help address this lacuna, this article has described the first large-scale audit study of discrimination against gay men in the United States. This study contributes to the literature on employment discrimination in three ways: by providing direct evidence about discrimination against gay men, by examining how discrimination varies across regions, and by exploring the role of stereotypes in discrimination. I elaborate on each these contributions below.

\section{Direct Evidence for Discrimination}

The first contribution of this study is that it provides more direct evidence for sexual orientation discrimination than do self-reports, small-scale experiments, and wage regressions. Employees' self-reports indicate subjective perceptions, which may not reflect the actual incidence of discrimination. Small-scale experiments test discrimination more directly but are limited in their generalizability and the extent to which they mimic real employment contexts. Wage regressions, in turn, examine data on a larger scale and show a pay gap between heterosexual and gay men, but skeptics might argue that this gap is due to unmeasured productivity differences rather than discrimination. To overcome these limitations, I have conducted an audit experiment. As Pager (2007, p. 120) noted, "Although the audit design cannot address all relevant aspects of labor market disadvantage, it can provide strong and direct measures of discrimination at the point of hire" (see also Correll et al. 2007). Indeed, by collecting 
data in several states, coding the characteristics of job postings, and matching the experimental results with employer data, this study produced more fine-grained evidence than many previous audit studies.

The results indicate that gay men encounter significant barriers in the hiring process because, at the initial point of contact, employers more readily disqualify openly gay applicants than equally qualified heterosexual applicants. Even after controlling for job, employer, and area characteristics, I found that gay job applicants were approximately $40 \%$ less likely to be offered a job interview than their heterosexual counterparts. This difference is similar in magnitude to the callback gap between black and white job seekers in a recent correspondence audit of Boston and Chicago employers (Bertrand and Mullainathan 2004). Overall, my findings are consistent with less direct indicators of discrimination against LGBT people (Badgett et al. 2007), and-taken together-these lines of evidence suggest that sexual orientation discrimination is a prominent feature of many American labor markets.

\section{Comparing Discrimination across Regions}

Audit studies of employment discrimination-whether they focus on race, gender, age, motherhood, or other characteristics-do not typically examine how the extent of discrimination varies geographically. For example, in the audit literature on racial discrimination in hiring, "no researcher has attempted to include more than two sites, thus limiting our comparative perspective on discrimination across labor markets" (Pager 2007, p. 120). Thus, we know little about how hiring discrimination against a given minority group might vary across regions, and it remains unclear whether cross-study differences in the observed level of discrimination reflect variation in experimental designs or regional variation in the incidence of discrimination.

To address these limitations, I have collected evidence from seven geographically dispersed states that vary in both the local attitudes toward gay men and the presence of laws that prohibit sexual orientation discrimination. The results indicate dramatic geographic variation in the level of discrimination, even after controlling for employer, industry, and occupational factors. While employers in the southern and midwestern states in the sample (Texas, Florida, and Ohio) showed strong discriminatory tendencies, there was little or no discrimination in the western and northeastern states, such as California, New York, and Pennsylvania.

This variation provides an interesting contrast to the cross-city variation observed in the audit literature on racial discrimination. Recent audit studies of discrimination against black job applicants (typically conducted in a midwestern or northeastern city) all documented some level 
of systematic discrimination (Pager 2007). In the case of gay job seekers, by contrast, while there was severe discrimination in some states, there was no discrimination at all in others. Of course, in the absence of a multistate audit study of racial discrimination, it is difficult to tell whether this difference is due to underlying differences in the geography of racial discrimination and sexual orientation discrimination or to the fact that recent audits of racial discrimination were typically limited to the Northeast and the Midwest. Indeed, more generally, my results suggest that focusing on a single geographic area may prevent audit studies from revealing the larger patterns of discrimination. Thus, a promising avenue for future research might be to study discrimination (on the basis of race, gender, age, motherhood, or other traits) with a multistate design similar to the one used in this study.

In addition to establishing the existence of regional variation in the level of sexual orientation discrimination, this study has begun to explore the sources of that variation. A key finding is that employers in states and counties with a relevant antidiscrimination law were significantly less likely to engage in discrimination, although this difference was no longer significant once I controlled for state-level attitudes. As noted earlier, however, we should interpret this result carefully. Clearly, this study relied on a small sample of states and-in the absence of reliable county- and city-level attitude data-it could not examine the relative impact of laws and attitudes within states. But, indeed, even if such data were available, it may not reveal the relationship between laws, attitudes, and discrimination in its entire complexity. For example, even if antidiscrimination laws had no direct effect, they may help reduce discrimination indirectly, by improving public opinion about gay people (Klawitter and Flatt 1998; Haeberle 2002). Of course, there is likely to be a causal effect in the opposite direction as well, as more tolerant local attitudes lead to more inclusive antidiscrimination laws. Given this potential joint causality between laws and attitudes, isolating their effects on discrimination is difficult (e.g., Burstein 1985). Future research might address this issue by exploring the relationship between attitudinal changes and the passage of antidiscrimination laws longitudinally, and perhaps by conducting repeated audits in a given set of states and cities over time.

Finally, it is important to bear in mind that this study has only examined the relationship between antidiscrimination laws and callback discrimination, rather than other forms of employment discrimination. Antidiscrimination laws, however, are often harder to enforce in the hiring process than in promotions, firings, or wage setting. As Petersen and Saporta (2004, p. 860) noted, those "not hired and possibly discriminated against will rarely know what occurred, and even when they do, it may be impossible to gather the relevant evidence." Thus, laws may be less effective 
in reducing discrimination against job seekers than against employees who are already on the firm's payroll (Jencks 1992).

\section{Stereotyping as a Mechanism}

The third main contribution of this study is that it identifies stereotyping as a potentially important mechanism underlying hiring discrimination against gay men. Employers who sought applicants with stereotypically male heterosexual traits were much more likely to discriminate against gay applicants than employers who did not emphasize the importance of such traits. This finding suggests that employers' implicit or explicit stereotypes of gay men are inconsistent with the image of an assertive, aggressive, and decisive employee. It seems, therefore, that the discrimination documented in this study is partly rooted in specific stereotypes and cannot be completely reduced to a general antipathy against gay employees.

This finding may also be considered in the framework of statistical discrimination (Arrow 1973), the practice of using "overall beliefs about a group to make decisions about an individual from that group" (Blank, Dabady, and Citro 2004, p. 61). For example, if employers believe that masculinity is associated with better job performance, believe that gay men on average are less masculine than heterosexual men, and cannot directly assess individual applicants' masculinity, they may judge job seekers on the basis of group averages. It is important to emphasize, however, that statistical discrimination "refers to situations of discrimination on the basis of beliefs that reflect the actual distributions of characteristics of different groups (Blank, Dabady, and Citro 2004, p. 61; emphasis added). If the overall beliefs about a group are simply based on stereotypes that stem from bias, then using such beliefs to make a decision about individuals is indistinguishable from "ordinary" nonstatistical discrimination (Blank et al. 2004). Thus, the statistical discrimination argument would apply in this case if the prevailing stereotypes of gay men as significantly more feminine or effeminate than heterosexual men reflected reality. Research on the validity of such stereotypes, however, has not been conclusive because of mixed results (e.g., Stokes, Kilman, and Wanlass 1983; Udry and Chantala 2006).

More generally, this study engages with a key question in understanding ascriptive inequality: How do members of dominant groups perceive the characteristics of subordinate groups, especially the characteristics that are relevant to inequality-generating decisions, such as hiring? (See Reskin 2001; Quillian 2006; Ridgeway 2009.) While this study does not provide direct access to the content of stereotypes, it demonstrates their potentially powerful effect on hiring decisions in real employment contexts. Thus, 
this study suggests that a fruitful path for future audit studies would be to explore the role that stereotypes play in discrimination on the basis of other characteristics, such as race, gender, age, or motherhood. As in this study, descriptions of desired personality traits in job ads may provide useful data for such research. Indeed, while there is a vast literature on stereotypes in sociology and social psychology, stereotyping has received little empirical attention in the audit literature (see Weichselbaumer [2004] for an exception). My findings suggest that this may be a missed opportunity. Although surveys and laboratory studies have demonstrated the strength and abundance of stereotypical beliefs about various groups, we know little about which of these stereotypes most potently affect decisions in actual labor markets. Since audit studies generate direct evidence of discrimination in real employment contexts, they seem particularly well suited to filling this gap.

\section{Résumé Matching and the Issue of Tactlessness}

Although the audit method has important advantages, it is not perfect. One particular challenge in correspondence audits is the need to match résumés so that they present two equally qualified applicants who differ only by the characteristic of interest. This may be a difficult challenge. For example, although distinctively African-American names may signal race reliably, they may also signal socioeconomic status, thus introducing a potential confound into the experiment (Pager 2007). Similarly, for instance, skeptics might argue that an officer position in a Parent-Teacher Association (Correll et al. 2007) may not simply signal parental status but also that the applicant is a particularly dedicated parent-a potentially important distinction. Naturally, audit researchers acknowledge these concerns and aim to minimize the distortions they may cause.

In audit studies that focus on sexual orientation, a particular issue is that listing involvement in a gay and lesbian organization may be seen as tactless (Weichselbaumer 2003). I took several steps to address this issue. First, I used résumés of college seniors, a population in which listing involvement in political, community, or identity-based organizations is not, in itself, a violation of prevailing norms. Second, to signal sexual orientation, I used a résumé item that emphasized highly relevant organizational and financial skills; indeed, omitting this item would have meant concealing important human capital. Third, my control organization could also potentially signal "tactlessness" and ensured that I was not detecting discrimination based on political views or activism.

Despite these precautions, the issue of tactlessness merits further discussion, especially because it is not unique to audit studies that focus on sexual orientation. Indeed, this issue might arise whenever the observed 
discrimination is based on a characteristic that is potentially concealable in the employee selection process—such as religion, political beliefs, or even motherhood and age (Armour 2003). How might audit studies deal with this issue? An empirical approach is to use a treatment organization that signals significant human capital and a control organization that rules out alternative explanations (such as political discrimination in this case). Another approach is to consider the implications of the tactlessness argument more carefully.

Presumably, the tactlessness argument assumes that applicants should know better than to list on their résumé any experience in an LGBT organization. Why should they know better? One possibility is that they should know that there indeed is discrimination against gay job seekers. In that case, even if a particular employer holds no bias against gay employees, he might discriminate against them for failing to conceal experiences in an LGBT organization. This is a possible scenario but it does not refute the existence of discrimination or imply that there is less discrimination than an audit study might reveal. Indeed, this scenario would occur precisely because there is discrimination against gay applicants (or at least employers assume there is, which in turn causes them to discriminate against gay applicants). Thus, rather than calling into question the results of audit experiments, this argument simply identifies one reason an individual employer might engage in discrimination. Future research that directly focuses on how employers evaluate résumés could examine this possibility.

Another version of the above argument might be that applicants should know better than to list an LGBT organization on their résumé because doing so violates a norm. But this argument, too, suggests discrimination against gay applicants. Otherwise, why would it be more acceptable to mention a treasurer position in a socialist group than a treasurer position in a gay and lesbian community organization, even in politically conservative areas? Indeed, college seniors' résumés frequently list activities in religious, political, ethnic, and other identity-based campus groups, so if the observed callback gap is due to a norm, that norm must be clearly directed against mentioning LGBT organizations and must be much stronger in the South and the Midwest than in the Northeast and the West. Thus, rather than refuting the existence of discrimination, this argument simply recasts it in terms of a norm that underlies, or stems from, discrimination.

A related issue is the concern that, for some reason, employers may perceive involvement in the control organization-in this case, the socialist/progressive organization-as more valuable than they see participation in the gay and lesbian organization. Some might argue, for example, that employers could perceive the socialist/progressive organization as 
more "intellectual" than the gay and lesbian organization. Or, perhaps, employers may see the socialist/progressive organization as an activist group that provides more opportunities to demonstrate leadership than the gay organization, which may be seen as focusing only partly on political activism. I addressed this issue in two ways. First, the randomly assigned résumé items specifically described the applicants' activities and achievements within each organization. Thus, rather than leaving it to the employers to guess what kind of activities the applicant pursued as part of his position, these résumé items provided specific information about those activities.

The second way to address this concern involves considering the empirical patterns that emerged from this study. If there were no discrimination against gay men but employers generally valued participation in the progressive/socialist group more highly that they valued experience in the gay/lesbian group (regardless of sexual orientation), we would expect a consistent penalty for the résumé with the gay signal in all areas. Yet, in reality, I only found such a penalty in some of the states. Thus, a compelling argument for confounding would need to explain why, in the absence of sexual orientation discrimination, employers in Texas and Ohio would make fundamentally different inferences about the value of these two résumé items than do employers in New York and California. Indeed, a convincing answer to this question would also need to address whyif sexual orientation itself did not matter-employers in more conservative states would favor the socialist/progressive applicant over the gay applicant.

\section{Adapting to the Reality of Discrimination}

This study documented the existence of discrimination, but it is left to future research to explore how gay job seekers adapt to this reality. Indeed, it is important to note that audit studies generally capture the extent of discrimination that occurs before job seekers' responses to discrimination-such as the avoidance of discriminatory employers-take place (Heckman 1998; Blank et al. 2004). In the case of sexual orientation, the issue of adaptation raises a particularly interesting dilemma. On the one hand, some might conclude that job applicants would be best advised to hide their sexual orientation during the hiring process and perhaps even beyond it, especially if employer bias extends to other decisions as well (e.g., about wages or promotions). If that is the case, disclosure may lead to a reduction in one's economic opportunities. On the other hand, concealment may also be costly. First of all, omitting relevant skills and experiences from one's work and volunteer history means hiding a potentially important part of one's human capital. Friskopp and Silverstein 
(1996, p. 186) noted in a study of Harvard Business School graduates: "Many of those we interviewed had significant leadership roles in various gay organizations but felt they could not include this information on their résumé without discrimination. Thus, by comparison to their heterosexual peers' resumes, theirs may have seemed devoid of outside activities and achievements, community involvement, or leadership skills. As [one respondent] confided, 'It looked sparse, but I didn't know what else to do.'”

In turn, once at the workplace, hiding one's sexual orientation is often stressful and may have a negative impact on the individual's productivity, self-esteem, depth of friendships, and ability to work as part of a team (e.g., Woods 1993; Friskopp and Silverstein 1996). Indeed, for these reasons, some might argue that it is in the interest of gay job seekers to signal their sexual orientation because doing so may screen out less tolerant employers. This strategy, of course, is only feasible if a sufficiently large number of nondiscriminatory employers offer equally high-quality jobs as their discriminatory counterparts (Pager 2007; Pager et al. 2009).

\section{Beyond the Callback Stage}

A related question is how employers treat openly gay applicants beyond the initial callback stage of the hiring process. One important factor in this regard might be whether interviewers differ from résumé screeners. If an openly gay applicant is interviewed by the same people who, aware of his sexual orientation, granted him a callback at the résumé stage, discrimination at the interview stage may be less likely than in cases when résumé screeners and interviewers are not the same people. In the latter case, not all interviewers may be as accepting of gay people as the résumé screener who made the initial selection. In addition, regardless of who the interviewers are, the interview phase may involve different discrimination-related processes than those present at the callback stage. On the one hand, to the extent that some aspects of "masculine" behavior are observable during this stage, interviewers may rely less on stereotypes and more on observations of individual attributes. On the other hand, research suggests that - at least in elite professional service firms-interviewers often pay particularly close attention to factors other than jobrelevant skills, such as extracurricular interests and personality traits, which they use to evaluate the "fit" of applicants to the firm and to distinguish between otherwise very similar candidates (Rivera 2009). Thus, because applicants who receive a callback are often similar in their grades and job-relevant experience, factors like sexual orientation-or involvement with an identity group based on sexual orientation-may become more salient at the interview stage than they were at the callback stage. In sum, the processes that foster or prevent discrimination are likely 
to vary across different stages of the hiring process; future research should explore these processes beyond the résumé-screening stage.

\section{Discrimination against Other Groups}

The scope of this study was limited to just one LGBT group-gay men. Thus, hiring discrimination against lesbian, bisexual, and transgender job seekers in the United States remains to be explored through large-scale audit studies. One path for future audit research would be to explore discrimination against lesbians. While survey-based research consistently documented a wage penalty for gay men, some studies found a wage premium for lesbians (Klawitter and Flatt 1998; Black et al. 2003). An audit study might offer insight into this intriguing result. Indeed, given that existing stereotypes of gay men and lesbians are significantly different (Madon 1997; Ward 2008), an audit study of stereotype-based employer behavior toward lesbians in the United States may be a particularly promising research endeavor (cf. Weichselbaumer 2003). Another avenue would be to explore the interaction of sexual orientation and race. For example, do race and sexual orientation interact to produce "multiple jeopardy" (King 1988) for LGBT members of racial minority groups? And, if there is such an interaction, does its nature vary across minority groups? Extending the current study to answer these questions would further deepen our understanding of labor-market inequalities.

Finally, future research might extend this study to enrich the broader literature on gender-based inequality. A particularly interesting question concerns the extent to which discrimination based on gender-as opposed to sexual orientation-would lead to similar empirical patterns as those observed in this study. For example, would heterosexual women also be disadvantaged in cases when employers emphasize stereotypically masculine traits? A promising first step toward exploring this question is an audit study by Weichselbaumer (2004), who found discrimination against women in traditionally male occupations in Austria and showed that this unfavorable treatment persisted even when female applicants' résumés signaled masculine personality traits. More generally, future research should benefit from simultaneously exploring the role of gender and sexual orientation in callback discrimination. In particular, large-scale audits covering multiple LGBT groups and both male and female applicants could help untangle both the direct and the interactive effects of gender and sexual orientation. 
APPENDIX

Signaling Sexual Orientation

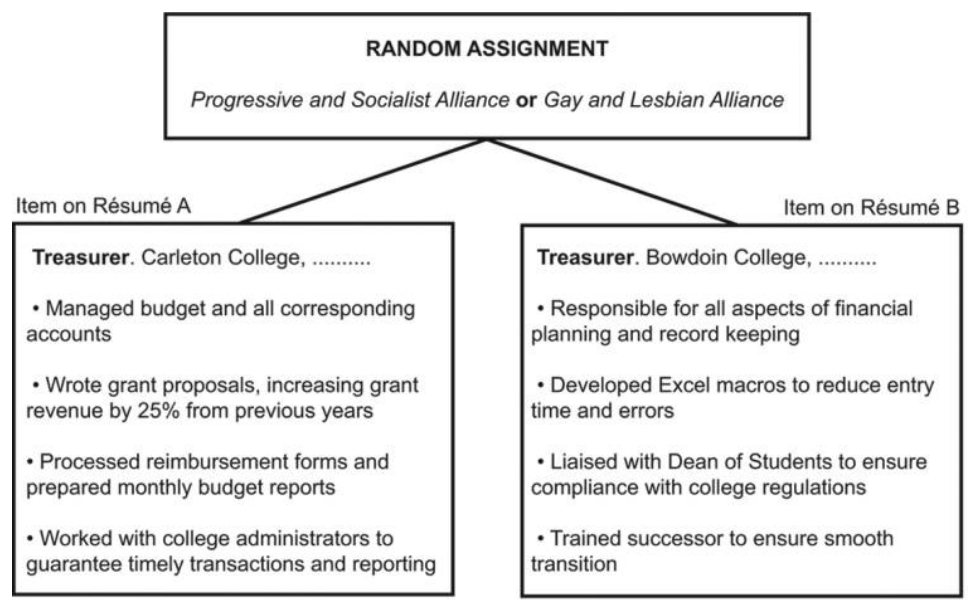

FIG. A1.-The fictitious applicants' colleges (Carleton on résumé A; Bowdoin on résumé B) are both private, independent, nonsectarian, coeducational liberal arts colleges. Both have been consistently ranked in very similar positions in popular college rankings, such as the U.S. News and World Report rankings, and both are located in states not sampled in this study (Maine, Minnesota). As mentioned in note 5 above, the two résumés did not differ in the number of callbacks they generated either in the overall sample or in subsamples by state and sexual orientation.

\section{REFERENCES}

$\rightarrow$ Adam, Barry. 1981. "Stigma and Employability: Discrimination by Sex and Sexual Orientation in the Ontario Legal Profession." Canadian Review of Sociology and Anthropology 18:216-21.

$\rightarrow$ Allegretto, Sylvia, and Michelle Arthur. 2001. "An Empirical Analysis of Homosexual/ Heterosexual Male Earnings Differentials: Unmarried and Unequal?" Industrial and Labor Relations Review 54:631-46.

$\rightarrow$ Antecol, Heather, Anneke Jong, and Michael Steinberger. 2008. "The Sexual Orientation Wage Gap: The Role of Occupational Sorting and Human Capital." Industrial and Labor Relations Review 61:518-43.

Armour, Stephanie. 2003. "More Job Seekers Try to Hide Their Ages." USA Today, July 20. http://www.usatoday.com/money/workplace/2003-07-20hide_x.htm.

Arrow, Kenneth J. 1973. "The Theory of Discrimination." Pp. 3-33 in Discrimination in Labor Markets, edited by Orley Ashenfelter and Albert Rees. Princeton, N.J.: Princeton University Press.

$\rightarrow$ Badgett, M. V. Lee. 1995. "The Wage Effects of Sexual Orientation Discrimination." Industrial and Labor Relations Review 48:726-39.

—. 1997. "Vulnerability in the Workplace: Evidence of Anti-Gay Discrimination." Angles: The Policy Journal of the Institute for Gay and Lesbian Strategic Studies 2:1-4.

2001. Money, Myths, and Change: The Economic Lives of Lesbians and Gay Men. Chicago: University of Chicago Press. 


\section{Openly Gay Men and Employment Discrimination}

Badgett, M. V. Lee, Colleen Donnelly, and Jennifer Kibbe. 1992. "Pervasive Patterns of Discrimination against Lesbians and Gay Men: Evidence from Surveys across the United States.” Washington, D.C.: National Gay and Lesbian Task Force Policy Institute.

Badgett, M. V. Lee, Holning Lau, Brad Sears, and Deborah Ho. 2007. "Bias in the Workplace: Consistent Evidence of Sexual Orientation and Gender Identity Discrimination." Report, Williams Institute, University of California School of Law.

Banaji, Mahzarin. 2002. "The Social Psychology of Stereotypes." Pp. 15100-104 in International Encyclopedia of the Social and Behavioral Sciences, edited by Neil Smelser and Paul Baltes. New York: Pergamon.

$\rightarrow$ Banaji, Mahzarin, Curtis Hardin, and Alexander J. Rothman. 1993. "Implicit Stereotyping in Person Judgment." Journal of Personality and Social Psychology 65:27281.

$\rightarrow$ Bem, Sandra. 1974. "The Measurement of Psychological Androgyny." Journal of Consulting and Clinical Psychology 42:155-62.

$\rightarrow$ Bendick, Marc, Jr., Lauren Brown, and Kennington Wall. 1999. "No Foot in the Door: An Experimental Study of Employment Discrimination." Journal of Aging and Social Policy 10:5-23.

$\rightarrow$ Berg, Nathan, and Donald Lien. 2002. "Measuring the Effect of Sexual Orientation on Income: Evidence of Discrimination." Contemporary Economic Policy 20:394414.

Berger, Joseph, Hamit Fişek, Robert Norman, and Morris Zelditch Jr. 1977. Status Characteristics and Social Interaction. New York: Elsevier.

$\rightarrow$ Bertrand, Marianne, and Sendhil Mullainathan. 2004. "Are Emily and Greg More Employable than Lakisha and Jamal? A Field Experiment on Labor Market Discrimination." American Economic Review 94:991-1013.

$\rightarrow$ Black, Dan, Makar Hoda, Seth Sanders, and Lowell Taylor. 2003. "The Earnings Effects of Sexual Orientation.” Industrial and Labor Relations Review 56:449-69.

$\rightarrow$ Blandford, John M. 2003. "The Nexus of Sexual Orientation and Gender in the Determination of Earnings." Industrial and Labor Relations Review 56:622-42.

Blank, Rebecca, Marilyn Dabady, and Connie Citro, eds. 2004. Measuring Racial Discrimination. Washington, D.C.: National Academy Press.

Burstein, Paul. 1985. Discrimination, Jobs, and Politics: The Struggle for Equal Employment Opportunity in the U.S. since the New Deal. Chicago: University of Chicago Press.

$\rightarrow$ Carpenter, Christopher. 2007. "Revisiting the Income Penalty for Behaviorally Gay Men: Evidence from NHANES III." Labour Economics 14:25-34.

Clain, Suzanne Heller, and Karen Leppell. 2001. "An Investigation into Sexual Orientation Discrimination as an Explanation for Wage Differences." Applied Economics 33:37-47.

Cohen, Jacob. 1969. Statistical Power Analysis for the Behavioral Sciences. New York: Academic Press.

Connell, Raewyn. 2005. Masculinities. Cambridge: Polity.

Cook County Commission on Human Rights. 2003. "Cook County Commission on Human Rights: Subject Matter Index.” http://www.cookcountygov.com/Agencies/ ccchr_2003_ruling_index.pdf.

$\rightarrow$ Correll, Shelley J., Stephen Benard, and In Paik. 2007. "Getting a Job: Is There a Motherhood Penalty?" American Journal of Sociology 112:1297-1338.

$\rightarrow$ Croteau, James M. 1996. "Research on the Work Experiences of Lesbian, Gay, and Bisexual People: An Integrative Review of Methodology and Findings." Journal of Vocational Behavior 48:195-209.

$\rightarrow$ Crow, Stephen M., Lillian Y. Fok, and Sandra J. Hartman. 1988. "Who Is at Greatest Risk of Work-Related Discrimination-Women, Blacks, or Homosexuals?" Employee Responsibilities and Rights Journal 11:15-26. 


\section{American Journal of Sociology}

$\rightarrow$ Davison, H. Kristl, and Michael J. Burke. 2000. "Sex Discrimination in Simulated Employment Contexts: A Meta-analytic Investigation." Journal of Vocational Behavior 56:225-48.

$\rightarrow$ Drydakis, Nick. 2009. "Sexual Orientation Discrimination in the Labour Market." Labour Economics 16:364-72.

$\rightarrow$ Farkas, George, and Keven Vicknair. 1996. "Appropriate Tests of Racial Wage Discrimination Require Controls for Cognitive Skill: Comment on the Paper by Cancio, Evans, and Maume." American Sociological Review 61:557-60.

Fiske, Susan T. 1998. "Stereotyping, Prejudice and Discrimination." Pp. 357-411 in The Handbook of Social Psychology, edited by Daniel T. Gilbert, Susan T. Fiske, and Gardner Lindzey. Boston: McGraw-Hill.

Friskopp, Anette, and Sharon Silverstein. 1996. Straight Jobs, Gay Lives: Gay and Lesbian Professionals, the Harvard Business School, and the American Workplace. New York: Scribner.

Gilbert, Dennis. 2001. Hamilton College Gay Issues Poll. Hamilton College, Clinton, N.Y. http:// www.hamilton.edu/news/gayissuespoll/analysis.html.

$\rightarrow$ Gorman, Elizabeth. 2005. "Gender Stereotypes, Same-Gender Preferences, and Organizational Variation in the Hiring of Women: Evidence from Law Firms." American Sociological Review. 70:702-28.

Gurwitz, Sharon, and Melinda Marcus. 1978. "Effects of Anticipated Interaction, Sex and Homosexual Stereotypes on First Impressions." Journal of Applied Social Psychology 90:173-83.

$\rightarrow$ Haddock, Geoffrey, Mark Zanna, and Victoria Esses. 1993. "Assessing the Structure of Prejudicial Attitudes: The Case of Attitudes toward Homosexuals." Journal of Personality and Social Psychology 65:1105-18.

Haeberle, Steven. 2002. "Testing Support for ENDA." Paper presented at the annual meeting of the American Political Science Association. Boston, August 28.

$\rightarrow$ Hebl, Michelle R., Jessica Bigazzi Foster, Laura M. Mannix, and John Dovidio. 2002. "Formal and Interpersonal Discrimination: A Field Study of Bias toward Homosexual Applicants." Personality and Social Psychology Bulletin 28:815-25.

$\rightarrow$ Heckman, James. 1998. "Detecting Discrimination." Journal of Economic Perspectives 12:101-16.

Herszenhorn, David. 2007. "House Approves Broad Protections for Gay Workers." New York Times, November 8. http://www.nytimes.com/2007/11/08/washington/ 08employ.html.

$\rightarrow$ Horvath, Michael, and Ann Marie Ryan. 2003. "Antecedents and Potential Moderators of the Relationship between Attitudes and Hiring Discrimination on the Basis of Sexual Orientation." Sex Roles 48:115-30.

Hull, Kathleen. 2005. "Employment Discrimination Based on Sexual Orientation: Dimensions of Difference." Pp. 167-88 in Handbook of Employment Discrimination Research, edited by Laura B. Nielsen and Robert L. Nelson. Dordrecht: Springer.

$\rightarrow$ Jackson, Linda, and Linda Sullivan. 1989. "Cognition and Affect in Evaluations of Stereotyped Members." Journal of Social Psychology 129:659-72.

Jencks, Christopher. 1992. Rethinking Social Policy. Cambridge, Mass.: Harvard University Press.

Johnson, Cathryn. 1995. "Sexual Orientation as a Diffuse Status Characteristic: Implications for Small Group Interaction." Pp. 115-37 in Advances in Group Processes, vol. 12. Edited by Barry Markovsky, Karen Heimer, and Jodi O'Brien. Greenwich, Conn.: JAI.

$\rightarrow$ King, Deborah. 1988. "Multiple Jeopardy, Multiple Consciousness: The Context of Black Feminist Ideology." Signs: Journal of Women in Culture and Society 14:88111

$\rightarrow$ Klawitter, Marieka, and Victor Flatt. 1998. "The Effects of State and Local Antidis- 
crimination Policies on Earnings for Gays and Lesbians." Journal of Policy Analysis and Management 17:658-86.

Lambda Legal. 2005. Summary of States, Cities, and Counties Which Prohibit Discrimination Based on Sexual Orientation. http://www.lambdalegal.org/cgibin/iowa/ news/resources.html?record=217. Accessed May 1, 2006.

$\rightarrow$ Lax, Jeffrey R., and Justin H. Phillips 2009. "Gay Rights in the States: Public Opinion and Policy Responsiveness." American Political Science Review 103:367-86.

Leape, Martha P., and Susan M. Vacca. 1995. The Harvard Guide to Careers, 5th ed. Cambridge, Mass.: Harvard University Office of Career Services.

$\rightarrow$ Madon, Stephanie. 1997. "What Do People Believe about Gay Males? A Study of Stereotype Content and Strength." Sex Roles 37:663-85.

$\rightarrow$ Morrison, Todd G., and Anomi Bearden. 2007. "Construction and Validation of the Homopositivity Scale: An Instrument Measuring Positive Stereotypes about Gay Men.” Journal of Homosexuality 52:63-89.

$\rightarrow$ Neal, Derek A., and William R. Johnson. 1996. "The Role of Premarket Factors in Black-White Wage Differences." Journal of Political Economy 104:869-95.

Padavic, Irene, and Barbara F. Reskin. 2002. Women and Men at Work, 2d ed. Thousand Oaks, Calif.: Pine Forge.

$\rightarrow$ Page, Stuart, and Mary Yee. 1986. "Conception of Male and Female Homosexual Stereotypes among University Undergraduates.” Journal of Homosexuality 12:10917.

$\rightarrow$ Pager, Devah. 2003. "The Mark of a Criminal Record." American Sociological Review 18: $937-75$.

$\rightarrow$ - 2007. "The Use of Field Experiments for Studies of Employment Discrimination: Contributions, Critiques, and Directions for the Future." Annals of the American Academy of Political and Social Science 609:104-33.

$\rightarrow$ Pager, Devah, Bruce Western, and Bart Bonikowski. 2009. "Discrimination in a LowWage Labor Market: A Field Experiment." American Sociological Review 74:77799.

$\rightarrow$ Petersen, Trond, and Ishak Saporta. 2004. "The Opportunity Structure for Discrimination." American Journal of Sociology 109:852-901.

Pew Research Center. 2003. "Religious Beliefs Underpin Opposition to Homosexuality." http://www.people-press.org/report/197/religious-beliefs-underpin-opposition-tohomosexuality.

Pinello, Daniel. R. 2003. Gay Rights and American Law. Cambridge: Cambridge University Press.

$\rightarrow$ Quillian, Lincoln. 2006. "New Approaches to Understanding Racial Prejudice and Discrimination." Annual Review of Sociology 32:299-328.

Reskin, Barbara. 2001. "Sex Stereotyping and Sex Bias in Employment." Pp. 1891-92 in Routledge International Encyclopedia of Women's Studies, edited by Cheris Kramarae and Dale Spender. New York: Routledge.

Riach, Peter, and Judith Rich. 2006. "An Experimental Investigation of Sexual Discrimination in Hiring in the English Labor Market." Berkeley Electronic Press Advances in Economic Analysis and Policy 6:1-20.

$\rightarrow$ Ridgeway, Cecilia L. 2009. "Framed Before We Know It: How Gender Shapes Social Relations." Gender and Society 23:145-60.

Rivera, Lauren A. 2009. "Hiring and Inequality in Elite Professional Service Firms." Doctoral dissertation. Harvard University, Department of Sociology.

Rubenstein, William B. 2002. "Do Gay Rights Laws Matter? An Empirical Assessment." Southern California Law Review 75:65-119.

$\rightarrow$ Rudman, Laurie A., and Peter Glick. 2001. "Prescriptive Gender Stereotypes and Backlash toward Agentic Women.” Journal of Social Issues 57:743-62.

Saad, Lydia. 2005. "Gay Rights Attitudes a Mixed Bag." Princeton, N.J.: Gallup News Service. May 20. 


\section{American Journal of Sociology}

$\rightarrow$ Stokes, Kirk, Peter R. Kilmann, and Richard L. Wanlass. 1983. "Sexual Orientation and Sex Role Conformity." Archives of Sexual Behavior 12:427-33.

$\rightarrow$ Udry, J. Richard, and Kim Chantala. 2006. "Masculinity-Femininity Predicts Sexual Orientation in Men but Not in Women." Journal of Biosocial Science, 38:797-809.

Ward, Jane. 2008. "Lesbian Stereotypes." Pp. 491-93 in Encyclopedia of Gender and Society, vol. 1. Edited by Jodi O'Brien. Thousand Oaks, Calif.: Sage.

Webster, Murray, Jr., Stuart Hysom, and Elise Fullmer. 1998. "Sexual Orientation and Occupation as Status." Pp. 1-22 in Advances in Group Processes, vol. 15. Edited by John Skvoretz and Jacek Szmatka. Greenwich, Conn.: JAI.

$\rightarrow$ Weichselbaumer, Doris. 2003. "Sexual Orientation Discrimination in Hiring." Labour Economics 10:629-42.

$\rightarrow-$ 2004. "Is It Sex or Personality? The Impact of Sex Stereotypes on Discrimination in Applicant Selection." Eastern Economic Journal 30:159-86.

Woods, James. 1993. The Corporate Closet: The Professional Lives of Gay Men in America. New York: Free Press. 